\title{
LED based solar simulator to study photochemistry over a wide temperature range in the large simulation chamber AIDA
}

\section{Magdalena Vallon, Linyu Gao, Feng Jiang, Bianca Krumm, Jens Nadolny, Junwei Song, Thomas Leisner} and Harald Saathoff

5 Institute of Meteorology and Climate Research, Karlsruhe Institute of Technology, 76344 Eggenstein-Leopoldshafen, Germany

Correspondence to: Harald Saathoff (ㅂarald.Saathoff@ kit.edu)

\section{Abstract.}

A light source has been built at the simulation chamber AIDA (Aerosol Interactions and Dynamics in the Atmosphere) at the

10 Karlsruhe Institute of Technology, simulating solar radiation at ground level. Instead of full spectra light sources, it uses a combination of LEDs with a narrow emission spectrum, resulting in a combined spectrum similar to the solar spectrum between 300 and $530 \mathrm{~nm}$. The use of LEDs leads to an energy-efficient, robust and versatile illumination concept. The light source can be used over a wide temperature range down to $-90^{\circ} \mathrm{C}$, is adjustable in intensity and spectral width as well as easily adjustable to new technological developments or scientific needs. Characterization of the illumination conditions shows a vertical intensity gradient in the chamber. The integral intensity corresponds to a $\mathrm{NO}_{2}$ photolysis frequency $\mathrm{j}\left(\mathrm{NO}_{2}\right)$ of $(1.58 \pm 0.21$ $(1 \sigma)) \times 10^{-3} \mathrm{~s}^{-1}$ for temperatures between 213 and $295 \mathrm{~K}$. At constant temperature, the light intensity is stable within $\pm 1 \%$. While the emissions of the different LEDs change with temperature, they can be adjusted, thus it is possible to adapt the spectrum for different temperatures. Although, the illumination of the simulation chamber leads to an increase of $0.7 \mathrm{~K} \mathrm{~h}^{-1}$ of the mean gas temperature, it is possible to perform experiments with aqueous droplets at relative humidities up to $\leq 95 \%$ and also above water or ice saturation with corresponding clouds. Additionally, temperature and wavelength dependent photolysis experiments with 2,3-pentanedione have been conducted. The photolysis of 2,3-pentanedione occurs mainly between 400 and $460 \mathrm{~nm}$ resulting in a mean photolysis frequency of $(1.03 \pm 0.15) \times 10^{-4} \mathrm{~s}^{-1}$ independent of temperature in the range 213-298 $\mathrm{K}$ with a quantum yield of $0.36 \pm 0.04$. In contrast the yield of the two main photolysis products, acetaldehyde and formaldehyde, decreases with temperature. Furthermore, the light source was applied to study the photochemistry of aerosol particles. For the atmospheric brown carbon proxy compound 3,5-diacetyl-2,4,6-trimethyl-1,4-dihydropyridine photochemical reaction products were identified. In aerosol particles containing iron oxalate as photosensitizer the photosensitized degradation of organic acids (pinic and pinonic acid) was studied. Although, the light source only generates about 1/3 of the maximum solar irradiation at ground level with a substantial intensity gradient throughout the simulation chamber it could be shown that this type of light source allows reproducible experiments over a wide range of simulated atmospheric conditions and with a large flexibility and control of the irradiation spectrum. 


\section{Introduction}

The interaction of light with the atmosphere is an important factor in understanding the physical and chemical processes influencing air quality and our climate. Alongside direct radiative effects, the interaction with clouds and aerosols, a mixture of either solid or liquid particles with gas, are significant. From a chemical viewpoint, light enables, besides the thermodynamic the photochemical pathway by lifting electrons in a higher energy level, thereby exiting the molecules. This leads to a multitude of reaction pathways which, without light would not be possible. Typical photochemical reactions like the formation of ozone and $\mathrm{OH}$-radicals or the fragmentation of halocarbon compounds have been studied widely in the last few decades, now offering a good understanding for the big picture. For the at least $10^{4}-10^{5}$ different organic compounds in the atmosphere the picture looks different and additional research is much-needed (Goldstein, 2007). The lack of a proper understanding of the influence of such compounds can also be seen in the high uncertainty of interaction of aerosols with light in the ICCP report (Stocker, 2013).

In principal photochemical reactions in the atmosphere can not only be categorized in inorganic and organic processes but also if they take place in gas or particle phase. Some substances are even only able to absorb in the ultraviolet to visible (UV-Vis) or enlarge their absorption cross section considerably by adsorbing at particles, thus breaking the symmetry of their molecule orbitals (Navea, 2017). A well-studied example is the chemisorption of $\mathrm{NO}_{3}{ }^{-}$to $\mathrm{Al}_{2} \mathrm{O}_{3}$ surfaces and subsequent photolytic reaction to $\mathrm{NO}_{2}$ (Baltrusaitis, 2007; Rubasinghege, 2009). But molecules do not have to fragment directly, especially more complex organic molecules can absorb the photon and transfer the excess energy to surrounding molecules leading to an enhanced fragmentation of substances which cannot absorb photons in the respective wavelength range themselves. Such molecules are called photosensitizers (Herrmann, 2015; George, 2015). In seawater, chlorophyll and humic acids take on this role. At the sea surface chlorophyll absorbs photons and reduces $\mathrm{Cl}^{-}$to the reactive $\mathrm{Cl}$ atoms (Reeser, 2009) and isoprene is being produced from nonanoic acids under the influence of humic acids (Ciuraru, 2015). Also aldehydes, acids (Rossignol, 2014; Monge, 2012; Aregahegn, 2013; Fu, 2015), metals and metal oxides have shown to act as photosensitizers in atmospherically relevant processes (overviews regarding the latter two can be found in Herrmann, 2015 and George, 2015).

55 By an increase of oxidation through solar irradiation more compounds with a low vapour pressure are likely to be formed also in the gas phase, thus forming new particles or condensing on existing particles. Consequently, light is not only contributing to the aging but also to the formation of new particles, increasing particle phase and consequently reactions which are only possible in liquid or solid phases (Navea, 2017). A lack of proper research methods to simulate atmospheric photochemistry therefore underestimates the formation of various, possibly harmful, components.

60 Apart from field measurements, controlled experiments in cloud simulation chambers offer the possibility to understand the atmospheric processes. One of these simulations chambers is the AIDA-chamber (Aerosol Interactions and Dynamics in the Atmosphere) at the Institute of Meteorology and Climate Research at the Karlsruhe Institute of Technology (KIT). It is one of the largest atmospheric simulation chamber which has a solid chamber wall, allowing temperatures down to $-90^{\circ} \mathrm{C}$, as well as cloud formation by adiabatic expansion (Möhler, 2003; Saathoff. 2003). The volume and temperature stability offers the 
possibility for long-term experiments with aerosols. Until now it didn't have the possibility to simulate solar irradiation, however, and as it has a solid aluminium casing it cannot use the natural sunlight like the Teflon chambers SAPHIR in Jülich (Bohn and Zilken, 2005; Rohrer et al., 2005), EUPHORE in Valencia (Wiesen, 2001; Zádor et al. 2006) or HELIOS in Orléans (Ren et al., 2017). To simulate some aspects of the atmospheric chemistry processes it is possible to generate ozone or $\mathrm{OH}$ radicals without a light source. But this only allows to simulate a limited part of atmospheric photochemistry. Other similar chambers have solved this issue by using either xenon arc lamps (CESAM chamber; Wang et al., 2011) fluorescent tubes or black light ( PACS-C3: Platt et al., 2013; Fankhauser et al., 2020) or single wavelength LEDs (CLOUD-chamber: Lehtipalo et al., 2018). LEDs and fluorescent tubes have the advantages that they are easy to use, emit less heat and are relatively costefficient. Nevertheless, they are not emitting in the full spectral range of the photochemical relevant spectrum, which should start at around $300 \mathrm{~nm}$ depending on the atmospheric height (solar spectrum see supplementary information) and reach at least until $500 \mathrm{~nm}$ to include photochemical reactions of chromophores found in organic matter (Sharpless, 2014). High-pressure xenon arc lamps on the other hand are emitting a spectrum similar to the solar spectrum with high intensities. However, they are difficult to handle due to their size and the risk of imploding light bulbs. Additionally the spectrum is often too broad making it necessary to apply filters, blocking part of the UV and the infrared radiation (Wang, 2011). So none of these solutions were favourable for the illumination of the AIDA chamber.

80 In the following we will describe the implementation of a newly designed light source for the AIDA chamber as well as the spectral characterization and photochemical characterization by the photolysis of $\mathrm{NO}_{2}$. Additionally, the results of temperature and wavelength dependent photolysis experiments of 2,3-pentanedione, will be presented and a first insight will be given into the photochemical aging of a brown carbon proxy and photosensitized decomposition of atmospherically relevant organic acids.

\section{Experimental overview}

\subsection{AIDA aerosol and cloud simulation chamber}

The AIDA simulation chamber at KIT is designed to simulate atmospheric conditions in the temperature range of $-90{ }^{\circ} \mathrm{C}$ to + $60^{\circ} \mathrm{C}$. It is comprised of an aluminium cylinder with a $4 \mathrm{~m}$ inner diameter and a torispherical head and bottom, resulting in a $7.5 \mathrm{~m}$ high chamber with a volume of $84.5 \mathrm{~m}^{3}$ and an inner surface area of $103 \mathrm{~m}^{2}$ (Saathoff, 2009). To recreate different

90 atmospheric pressures and to facilitate the cleaning of the chamber, the pressure inside the vessel can be adjusted between 0.01 $\mathrm{hPa}$ and $1500 \mathrm{hPa}$. Various flanges and lances are implemented and allow the addition of synthetic air, chemicals or aerosols as well as the mounting of different measurement instruments. By rotating with 400 revolutions per minute, a fan inside the chamber enables homogeneous dispersion of all components in less than 2 minutes. A more detailed description of the chamber can be found in Wagner et al., 2006, Saathoff et al., 2003 and Müller at al., 2012. 


\subsection{Instrumentation}

For the spectral measurements three different UV-Vis-Spectrometer were used. For continuous monitoring during the experiments a UV-Vis Spectrometer (CCS200-Thorlabs) is connected via an optical fibre to the AIDA bottom looking inside the chamber via an off-axis parabolic mirror and through a quartz window. For the spatially resolved measurements inside the chamber two calibrated UV-Vis spectrometer with diffusor heads were used (SR900HS, Opsytec; LI-1800 LICOR). Please note, that the spectra measured with the fibre coupled spectrometer show a bias compared to the calibrated ones essentially significantly underestimating the UV wavelengths.

The concentrations of the trace gases were measured with different gas sensors. For nitrogen dioxide the cavity phase shift $\mathrm{NO}_{2}$ Analyzer (AS32M Environment S. A.), for nitrogen oxide the chemiluminescence NO analyser (CLD 77AM Eco Physics) and for ozone the UV photometric ozone monitor (O3 41M Environment S. A.) were used. All of these gas sensors are connected to the chamber through FEP-tubes.

For the concentration measurements of 2,3-pentanedione and its reaction products, a proton transfer mass spectrometer (PTRTOF-MS 4000, Ionicon, hereafter PTR-MS) was connected via SilcoNert coated stainless tubes to the AIDA chamber, measuring the gas phase continuously. The PTR-MS is a time-of-flight mass spectrometer, ionizing organic components by transferring a proton from $\mathrm{H}_{3} \mathrm{O}^{+}$to the analyte (Romano et al., 2015; Yuan et al. 2017). Furthermore, the PTR-MS coupled

110 with the particle inlet of CHARON (Chemical Analysis of Aerosol Online) can be alternatively switched between particle and gas phase for the particle phase measurement of semi-volatile compounds. In addition, a chemical ionization mass spectrometer (HR-ToF-CIMS, Aerodyne Inc., hereafter CIMS) ionizing with iodide ( $\left.\mathrm{I}^{-}\right)$with high sensitivity for highly oxidized organic molecules. Its FIGAERO attachment (Filter Inlet for Gases and AEROsols) allows the sampling of aerosol particles on Teflon filters, the subsequent heating of the filters to $200^{\circ} \mathrm{C}$ to evaporate the particle phase components into the gas phase, and

115 detection by the CIMS (Lopez-Hilfiker, 2014). To ensure gas phase analysis at the chamber throughout the experiments, aerosol filters were taken separately, stored at $-20^{\circ} \mathrm{C}$ in individual containers and analysed as soon as the experiments were completed.

\subsection{Experimental procedures}

For all photochemical experiments the chamber was cleaned by evacuating and flushing repeatedly with synthetic air and ozone. Afterwards it was filled with a defined amount of water vapour and synthetic air $\left(21 \% \mathrm{O}_{2}, 79 \% \mathrm{~N}_{2}\right)$ generated by evaporating liquid nitrogen (class 2.2 (C/E), AirProducts) and liquid oxygen (4.8 - $99.998 \mathrm{Vol} \%$, Basi).

For the $\mathrm{NO}_{2}$-photolysis experiments, 40-70 ppb of $\mathrm{NO}_{2}$ (1000.3 ppm NO 2.5 in $\mathrm{N}_{2}$ 5.0, Basi) were added to the chamber and illuminated for $40 \mathrm{~min}$. The light source was operated at the highest intensity possible for every temperature.

For the photolysis of 2,3-pentanedione, 66-71 ppb and in one case $20 \mathrm{ppb}$ of 2,3-pentanedione were added to the chamber

125 either to the pure synthetic air or after a photochemical experiment with $\mathrm{NO}_{2}$. For the temperature dependent photolysis experiments the light source was used in the same intensity for each temperature as for the corresponding temperature in the 
photolysis of $\mathrm{NO}_{2}$, illuminating for 60-65 min. Additionally 2,3-pentanedione was irradiated for intervals of 15 min using a different range of wavelengths for every interval.

For the photolysis of the brown carbon proxy two solutions were prepared each containing $\mathrm{NH}_{4} \mathrm{NO}_{3},\left(\mathrm{NH}_{4}\right)_{2} \mathrm{SO}_{4}$ and 3,5diacetyl-2,4,6-trimethyl-1,4-dihydropyridine (hereafter DTDP). One solution contained a commercial DTDP (Sigma-Aldrich, 97\%) ( $\left.2.00 \mathrm{~g} / 1 \mathrm{NH}_{4} \mathrm{NO}_{3}, 1.221 \mathrm{~g} / 1\left(\mathrm{NH}_{4}\right)_{2} \mathrm{SO}_{4}, 1.11 \mathrm{~g} / \mathrm{l} \mathrm{DTDP}\right)$ for the second solution the DTDP was prepared in the laboratory by using acetaldehyde (44.34 g/l, Acros Organics 99,5\%), 2,4-pentanedione (100.22 g/l, Alfa Aesar 99\%) and $\left(\mathrm{NH}_{4}\right)_{2} \mathrm{SO}_{4}(132.16 \mathrm{~g} / \mathrm{l})$ according to Kampf et al., 2016. In this way the atmospheric processes leading to the formation of the brown carbon proxy were imitated and potential by-products would also appear in the solution. The solutions were nebulized into the chamber using an ultrasonic nebulizer (Synaptec) and illuminated for $120 \mathrm{~min}$.

To mimic photosensitized decomposition of organic acids, a solution of $\mathrm{NH}_{4} \mathrm{NO}_{3}$, iron oxalate $\left(\mathrm{C}_{6} \mathrm{Fe}_{2} \mathrm{O}_{12}\right.$, Sigma-Aldrich) as the photosensitizer and pinonic (Acros Organics 98\%) and pinic acid ( 95\% synthesized by University of Frankfurt) as atmospherically relevant organic acids, was nebulized in the chamber and illuminated twice, each time for one hour. As a reference the experiment was repeated with a solution of oxalic acid, pinonic acid and $\mathrm{NH}_{4} \mathrm{NO}_{3}$. A detailed overview of the concentrations and experimental characteristics can be found in the supplementary information (Table S1).

\section{Construction of the light source}

The design criteria for the light source for the AIDA chamber were: (1) The spectrum of the light source should allow to mimic the solar spectrum in the troposphere, but should be variable in intensity and wavelength range, to allow simulation of different atmospheric heights as well as wavelength specific photolysis experiments. (2) The light source should affect the temperature homogeneity and the leak tightness of the chamber as little as possible. It should work in the temperature range from $303 \mathrm{~K}$ to $183 \mathrm{~K}$, be energy efficient, easy to handle, maintain and improve or adapt to new technical developments. With these, classical solutions like arc lamps or fluorescent tubes were ruled out. Instead, a light source was designed by using a combination of LEDs with a small full width at half maximum (FWHM) ( 10-15 nm) and peak wavelengths from $305 \mathrm{~nm}$ to $528 \mathrm{~nm}$. In total 3000 LEDs covering 11 different wavelengths were used, leaving out the longer wavelengths above $530 \mathrm{~nm}$. All the LEDs were tested beforehand to ensure their functionality at temperatures down to $183 \mathrm{~K}$ and their emission spectrum regarding changes with temperature and operating with different electric current was characterized. For the most part, spectral changes regarding the electrical current were minor and can be neglected. On the other hand, temperature changes are influencing the emission spectrum substantially. In general, a shift in the peak wavelengths of up to $5 \mathrm{~nm}$ could be observed while changing the ambient temperature from $298 \mathrm{~K}$ to $183 \mathrm{~K}$. The intensity increased or decreased depending on the manufacturer and LEDtype by up to $+60 \%$ or $-50 \%$ (examples for LEDs with a wavelength of $340 \mathrm{~nm}$ and $365 \mathrm{~nm}$ are available in the supplement). For every LED-type which underwent a decrease in intensity, the reduction could be counteracted by increasing the electric current at the respective temperature. To prevent degradation of the LED-lenses due to aggressive chemicals, the light source was not installed inside the chamber but on top of the chamber on three aluminium heat sinks mounted above flanges with a 
diameter of $500 \mathrm{~mm}$ (fig.1b-d). Each flange lid contains three CF flanges (VPCF200UVQ-L, VACOM) with quartz windows (Fused Silica, Corning HPFS 7980) with a thickness of $9 \mathrm{~mm}$ and a diameter of $200 \mathrm{~mm}$ each. Resulting in a total of 9 windows for the light to pass through into the chamber (see Fig.1a and c). The flanges are mounted at an angle of $14^{\circ}$ on top of the chamber, so that the incoming light forms three conical radiation paths overlapping in the middle of the chamber. The different LED types were distributed as homogeneously as possible over the three flanges. The volume between the LEDs and the quartz windows is constantly flushed with dry nitrogen $\left(20 \mathrm{~min}^{-1}\right)$ during operation to avoid condensation of water and build-up of ozone, helping also with reducing the heat. To avoid unnecessary irradiation losses, stripes of eloxated aluminium mirrors (MIRO 4300UP, alanod) were installed between the windows and the LEDs and at the inner part of the $500 \mathrm{~mm}$-flanges (see fig. 1b). The cooling rate of the heat sinks $\left((60 \times 60) \mathrm{cm}^{2}\right.$, JK 2907, Junior Kühlkörper GmbH) is enforced by 5 fans $(8218$ JH4, Ebmpapst) per heat sink, forcing the air through the gills of the heat sinks. To monitor the temperature of the LED boards, 28 temperature sensors (Pt1000) are placed on top of different boards. During operation the LED boards heat up to a maximum of $344 \mathrm{~K}$ at room temperature. All the electronical parts are connected to two 19" racks outside of the chamber isolation, containing all the necessary power supplies for the LEDs , the components to control the power supplies (cRio-9066, National Instruments), as well as the modules to process the temperature signals (NI-9226, NI-9264, NI-9476, NI-9209, NI-9221, National Instruments). A general connection scheme can be found in the supplementary information. The whole setup is controlled by a specifically written software (LabVIEW, National Instruments). It allows to control the LEDs intensity for every wavelength, reads the actually flowing electric current as well as the temperatures. Maximum values for the electric current and the temperatures can be set by the user, leading to an automatic shutdown of the light source if one of these values is exceeded. The UV-Vis spectrometer (CCS200, Thorlabs) installed at the bottom of the chamber, measuring constantly the light spectrum inside the chamber, serves as an additional control mechanism to ensure constant irradiation is achieved during the experiments. 

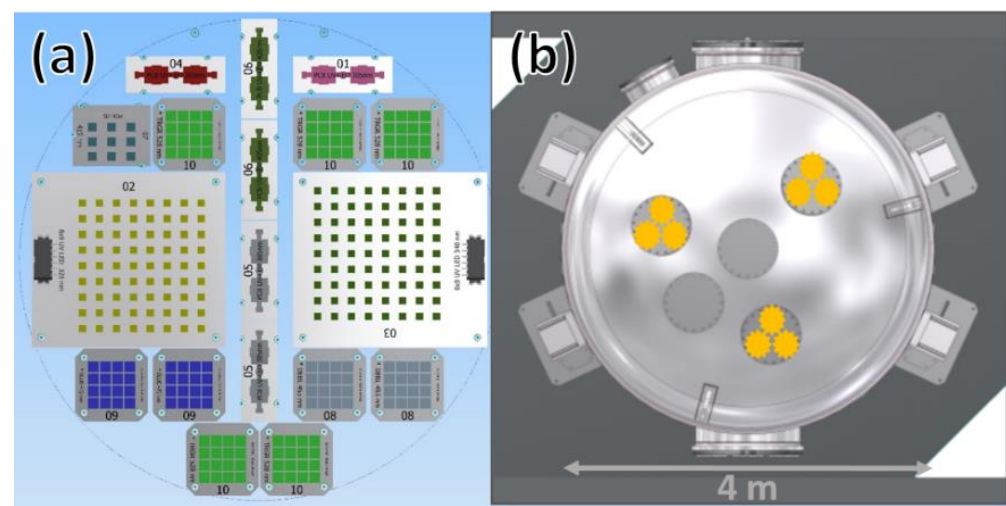

(d)
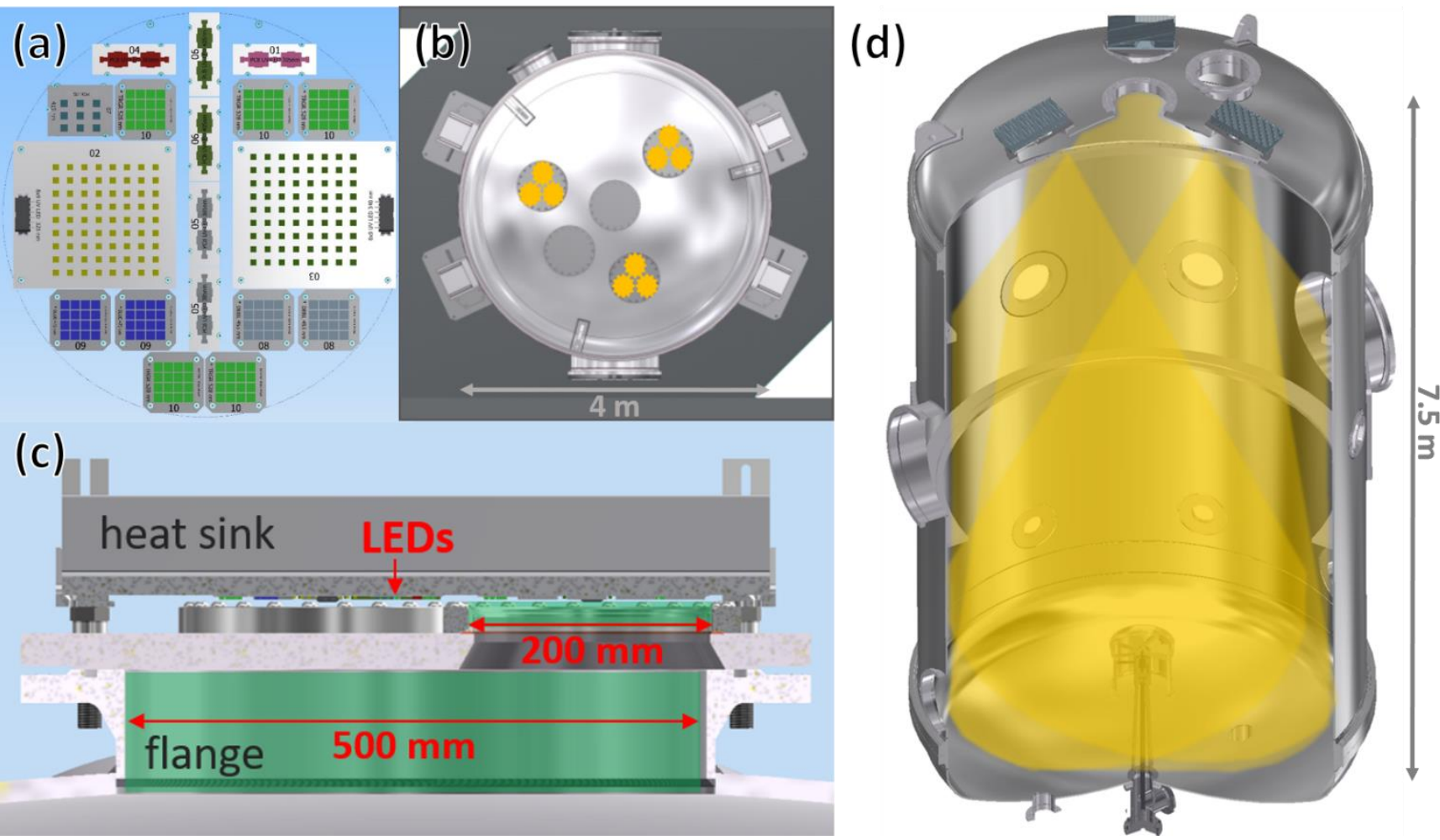

Figure 1: a) LED board placement matching one $200 \mathrm{~mm}$ window. b) Three of these patches are placed on one heat sink above the $500 \mathrm{~mm}$ flange with three $200 \mathrm{~mm}$ quartz windows. c) Placement of the flanges and the windows on top of AIDA. d) Placement of the light source in relation to the whole AIDA with corresponding light cones.

\section{Characterisation of the light source}

185 The total radiative output of all LEDs amounts to $1400 \mathrm{~W}$, while the UV-LEDs have efficiencies of only 2\%, the LEDs with longer wavelengths reach efficiencies of 30 to $70 \%$. The optical power is distributed over the different wavelengths and over the chamber cross-section. For a proper characterization of the illumination, spatially resolved spectral and integral actinometric measurements were performed.

\subsection{Spectral and spacial characteristics}

190 The combined emission of all the LEDs results in a spectrum, similar but not identical to the solar spectrum at ground level. Measurements in the centre of the chamber (see Fig. 2a) show that the spectral distribution matches the solar spectrum by overlapping of the single LED-spectra. Only at $357 \mathrm{~nm}$ and $440 \mathrm{~nm}$ are discrepancies due to the fact that LEDs with a peak wavelength in that region and high efficiency are, to our knowledge, not yet available. The intensity and to a lesser extent the spectral distribution is dependent on the position in the chamber. Due to the conical dispersion of the light the irradiated area increases quadratically and the intensity of the light reduces accordingly. This effect and the absorption of light on the walls 
leads to strong vertical but smaller horizontal gradient in intensity. Measurements show that the light intensity in the centre of the chamber at about $1 \mathrm{~m}$ above ground level represents $45 \%$ of the intensity at a height of $4 \mathrm{~m}$. This can be further divided into the different parts UV-B (280-315 nm), UV-A (315-400 nm) and visible light (400-620 nm). The absorption of light with shorter wavelengths by the chamber walls and flange collar, is stronger than for the light with longer wavelength, resulting in a reduction of the UV-parts in comparison to the visible part. This is also in accordance with the reflectivity of non-oxidized aluminium which shows a maximum in reflectivity at around $400 \mathrm{~nm}$ (Bartl and Baranek, 2004) Comparing the values of the measurements at $1 \mathrm{~m}$ and $4 \mathrm{~m}$ the UV-B at $1 \mathrm{~m}$ represents $32 \%$, the UV-A represents $43 \%$ and the visible $47 \%$ of the values at $4 \mathrm{~m}$. The absorption on the walls and the overlapping of the light cones in the middle of the chamber also lead to a slight radial intensity gradient (see Fig. 2b). At $1.20 \mathrm{~m}$ left and right to the chamber centre at $1 \mathrm{~m}$ height the light intensity is on average $86 \%$ of the light intensity in the centre at the same height.
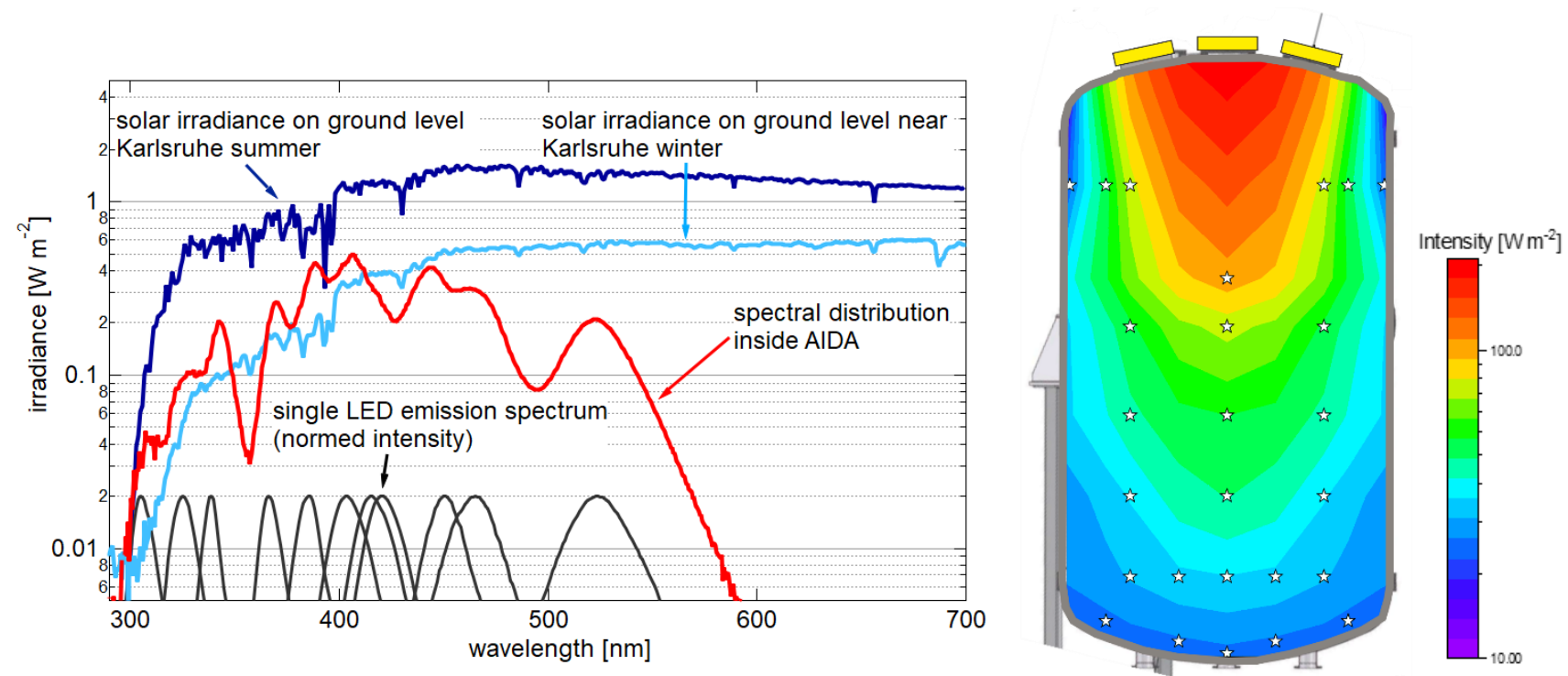

Figure 2: a) Light spectrum inside the AIDA chamber, measured at a central position at a height of $2.9 \mathrm{~m}$ above the chamber floor. Solar irradiance for winter was measured with a calibrated spectrometer at KIT. The solar irradiance for summer is calculated with the NCAR UCAR Quick TUV model (further information in the supplement). b) Light intensity distribution interpolated based on measurements at 26 different positions (white stars) inside the AIDA chamber.

\subsection{Stability of the light source}

At a constant temperature, the emission of the light is also constant in intensity, thus offering reproducible illumination conditions. As the emission of the LEDs themselves is temperature dependant, the resulting spectra in the chamber change slightly with temperature. This also leads to the effect that after switching on the LEDs it takes less than 3 min until the LEDs have reached a constant operating temperature. After this initial period the light emission remains constant within $\pm 0.02 \%$ (see Fig. 3b). This effect is less pronounced at warmer temperatures. The overall variability is less than $1 \%$ at constant temperature. Additionally the LEDs can be operated at higher electrical currents at lower temperatures, changing the emitted 
spectrum further with typically higher emissions for lower wavelengths (cf. Fig. 3a). Alternatively, it would be possible to apply lower currents at lower temperatures to keep the emission spectrum nearly constant compared to warmer conditions.
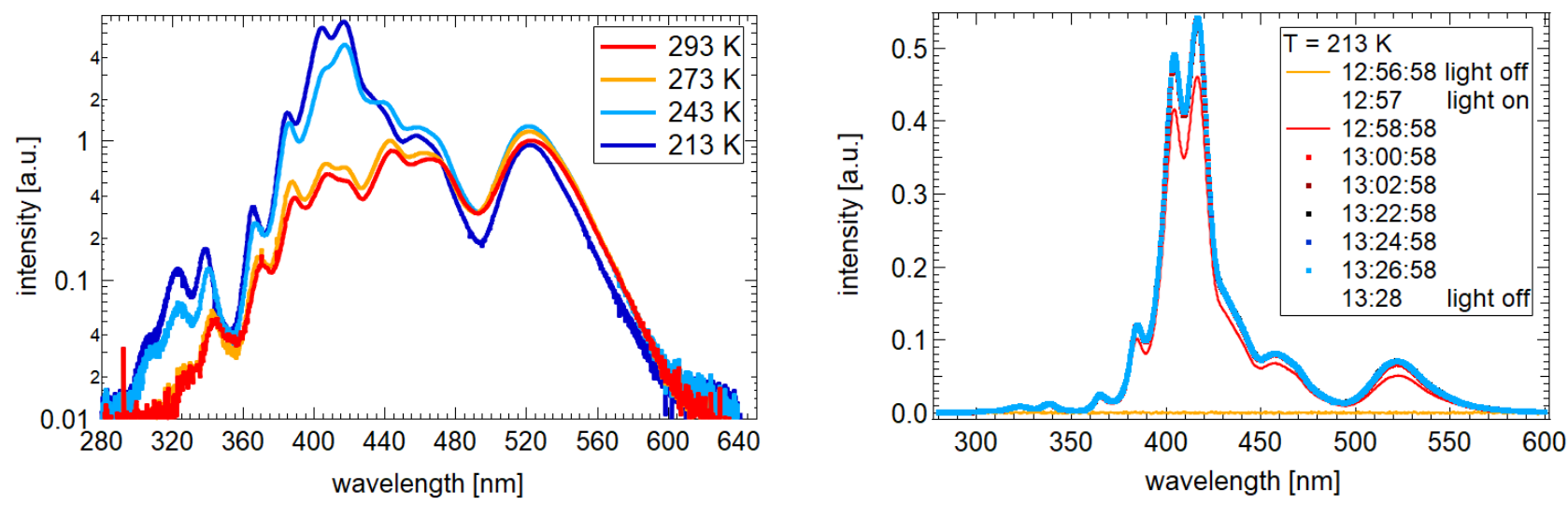

Figure 3: a) Spectra taken with the UV-Vis spectrometer at the bottom of the chamber at 4 different temperatures. The electrical settings for the LEDs for each temperature are different. In addition to the emission changes of the LEDs due to the temperature variation, this leads to different spectral distributions for each temperature. b) Spectra taken with the UV-Vis spectrometer at the bottom of the chamber over a time period of $30 \mathrm{~min}$.

\subsection{Integral light intensity}

The actinometric experiments, by using the photolysis of $\mathrm{NO}_{2}$ inside the chamber, provide photolysis frequencies for every measured temperature and light setting. Thus offering reference values of the light intensity for comparison with other simulation chambers or with solar irradiation. The photolysis of $\mathrm{NO}_{2}$ can be described with the following three equations, neglecting further side reactions (Harvey et al., 1977; Holmes et al., 1973).

$$
\begin{aligned}
& \mathrm{NO}_{2}+h v \stackrel{k_{1}}{\rightarrow} \mathrm{NO}+\mathrm{O} \\
& \mathrm{O}+\mathrm{O}_{2}+\mathrm{M} \stackrel{k_{2}}{\rightarrow} \mathrm{O}_{3}+\mathrm{M} \\
& \mathrm{NO}+\mathrm{O}_{3} \stackrel{k_{3}}{\rightarrow} \mathrm{NO}_{2}+\mathrm{O}_{2}
\end{aligned}
$$

235 The actinometric experiments were carried out at eight different temperatures (213, 243, 263, 268, 273, 283, 295 and $296 \mathrm{~K})$ in dry synthetic air, each with the highest light intensity setting possible, for long term use. Figure 4a shows pressure, temperature and the concentrations of the trace gases of one of these experiments. Please note that the instantaneous steps of $0.1 \mathrm{~K}$ in temperature when switching on and off the light is due to radiative heating of the sensors inside the chamber but not reflecting a sudden change in gas temperature. After turning on the light the $\mathrm{NO}_{2}$-concentration decreases and the $\mathrm{NO}$ - and $\mathrm{O}_{3}$-concentration rise, the system reaches a dynamic equilibrium after 10-12 min. Using the equilibrium concentrations and assuming a quasi-stationary state for ozone, the photolysis frequency is calculated by using the following equation and the reaction rate constant $\mathrm{k}_{3}=2.07 \times 10^{-12} \exp (-1400 \mathrm{~K} / \mathrm{T})\left[\mathrm{cm}^{3}\right.$ molecule $\left.{ }^{-1} \mathrm{~s}^{-1}\right]$ as recommended by IUPAC (Atkinson et al., 2004). 
$j\left(\mathrm{NO}_{2}\right)=\mathrm{k}_{3} \frac{\left[\mathrm{O}_{3}\right][\mathrm{NO}]}{\left[\mathrm{NO}_{2}\right]}$

The resulting photolysis frequencies for the different temperatures are shown in Fig. 4b. They vary slightly, resulting in a mean

value of $(1.58 \pm 0.21(1 \sigma)) \times 10^{-3} \mathrm{~s}^{-1}$. Additionally, one experiment was done in pure nitrogen but leading to very similar results. In comparison, the maximum values for a clear winter and a summer day in Karlsruhe are $3.4 \times 10^{-3} \mathrm{~s}^{-1}$ and $6.0 \times 10^{-3} \mathrm{~s}^{-1}$ (calculated with the Quick TUV Calculator of NCAR UCAR). Thus, one hour of illumination in the AIDA chamber corresponds to half an hour solar illumination on a clear winter day at ground level. Regarding the size of the chamber, this is a significant value. The biggest chamber of PACS-C3 $\left(27 \mathrm{~m}^{3}\right)$ at Paul Scherrer Institute in Switzerland achieves a $\mathrm{NO}_{2}$ photolysis frequency of $2.0 \times 10^{-3} \mathrm{~s}^{-1}$ by combining arc xenon lamps and black-light lamps (Paulsen et al., 2005). By using three $4 \mathrm{~kW}$ high-pressure arc xenon lamps for the CESAM-chamber $\left(4.2 \mathrm{~m}^{3}\right)$ at the Interuniversitary Laboratory of Atmospheric Systems in Paris a photolysis frequency of $4.2 \times 10^{-3} \mathrm{~s}^{-1}$ is achieved (Wang et al., 2011). Since the chamber is higher than other chambers compared to the base area and the LED emissions are conical, uniform and intense illumination is particularly difficult. Being at the lower end of the illumination intensities still significant improvements based on the fast development of LEDs in the near future seems possible.
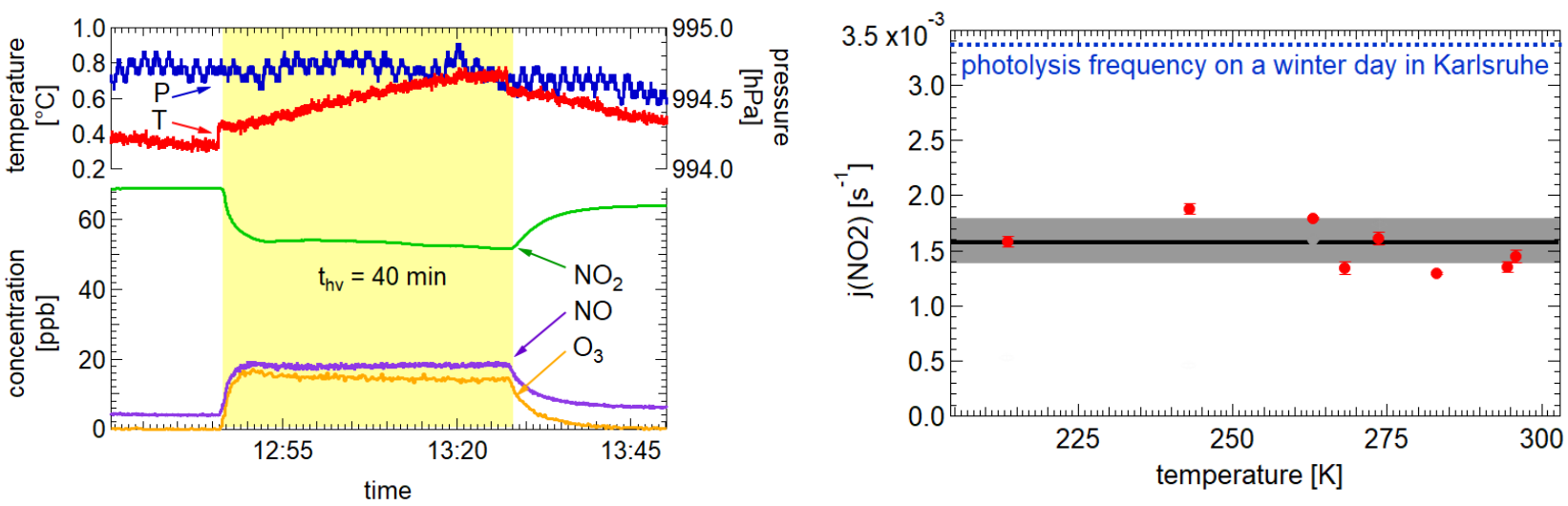

Figure 4: Pressure, temperatures and concentrations during an actinometric experiment with $\mathrm{NO}_{2}$. The resulting photolysis frequencies at the different temperatures.

By constructing the light source as a combination of LEDs we achieved an illumination with a similar spectral distribution as the solar light at ground level as well as intensities which allow to simulate realistic conditions of the atmospheric illumination. Furthermore the light source has only a small impact on the temperature stability of the chamber. The average gas temperature increases by $0.7 \mathrm{~K}$ per hour for the first 2 hours of illumination with maximum power. This ensures stable simulation conditions and allows the illumination of clouds at relative humidities close to and above water or ice saturation. An example for this is shown in Fig. S9. The light source itself can be operated safely between $183 \mathrm{~K}$ and $303 \mathrm{~K}$ and the irradiation spectrum can be changed at any point also during the experiments without technical difficulties. This is especially advantageous in comparison to xenon arc lamps which get very hot and are difficult to handle, for example if one would like to adjust the spectrum by 
adding or removing a filter. Especially important for future uses is the light sources adaptability. LEDs can be replaced or added whenever there is a new technological development or scientific needs e.g. by adding UV-C LEDs.

\section{Photolysis of 2,3-pentanedione}

Studying the photolysis of 2,3-pentanedione in the gas phase demonstrates also the possibilities the new AIDA light source offers. 2,3-Pentanedione itself is a yellowish liquid which is used in the food industry for fragrance and flavouring (Burdock, 2002). But it is also emitted into the atmosphere through biological processes in vine and pine trees or formed by ozonolysis of alkenes (Burdock, 2002; Campo et al., 2006; Grossjean et al.;1998). Furthermore as an alpha carbonyl component, it can be used as a proxy for similar molecules. Carbonyl components can decompose in the atmosphere through photochemical pathways, forming radicals (Tadić et al., 2006). The primary photolysis step of 2,3-pentanedione can lead to different radicals with thresholds at around 340, 350, and $400 \mathrm{~nm}$ (Bouzidi et al. 2015; Szabo et al., 2011; Kercher et al., 2005). An overview of different reaction pathways for the photolysis of 2,3-pentanedione is given in Bouzidi et al. (2014 and 2015). Besides $\mathrm{CO}_{2}$ and $\mathrm{CO}$, the main products of these reaction pathways are acetaldehyde and formaldehyde (Szabo et al., 2011).

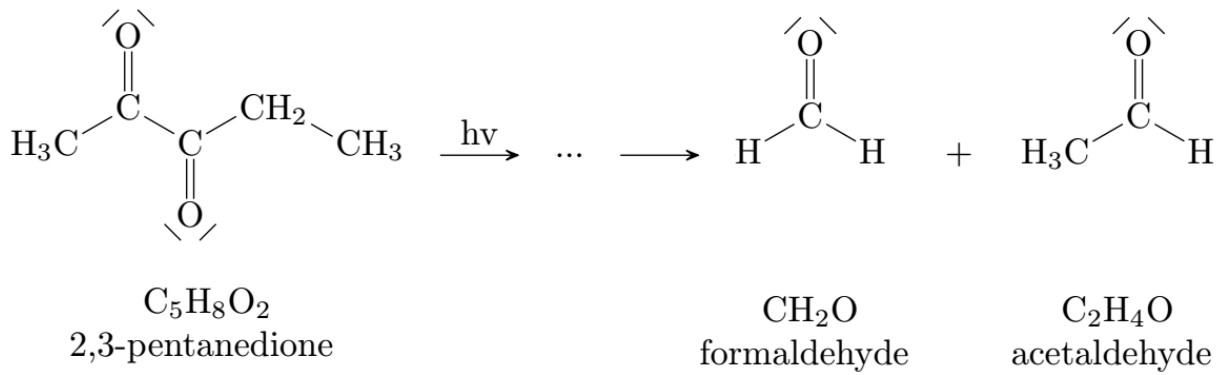

The aim is to improve the current knowledge about the decomposition behaviour of $\alpha$-carbonyls and especially 2,3pentanedione in the atmosphere. For this purpose photolysis frequencies and product distributions were determined as a function of temperature and wavelength of the irradiation.

\subsection{Variation of temperature}

The photolysis frequency $\mathrm{j}$ of a molecule is not only dependent on the incoming radiation I but also on the quantum yield $\phi$, which for photolysis is defined by the actual number of bond cleavages divided by the number of absorbed photons, and the absorption cross section $\sigma$ of the respective substance. The latter two as well as the product yields can be temperature dependent (Seinfeld and Pandis, 2006).

$290 j=\int_{\lambda_{1}}^{\lambda_{2}} \sigma(\lambda, T) \Phi(\lambda, T) I(\lambda) d \lambda$

As temperature dependencies of the photolysis of other components like $\mathrm{NO}_{2}$ (Shetter et al., 1988), ozone (Smith et al., 2000) or o-methylacetophenon (Scaiano, 1980) are minor it is to be expected that this is also the case for 2,3-pentanedione. But as 
acetylaldehyde and formaldehyde are not the direct photolysis products, a temperature dependence of their formation cannot be ruled out. Thus the photolysis frequencies, quantum yields, and the product yields were determined in a series of experiments at five different temperatures $(213,243,273,283,298$ K). Employing the PTR-MS the mass concentrations of acetaldehyde and formaldehyde in the gas phase were measured (see Fig. S4 in supplement). The photolysis frequencies are calculated by regarding the photolysis as a first-order reaction. This is justified as the data show a linear behaviour on a logarithmic scale. The slope of the line allows to calculate the photolysis frequency for the respective experiment (see Fig. 5). The concentration of 2,3-pentanedione decays due to photolysis but especially for the lower temperatures also due to the adsorption of molecules from the gas phase at the chamber walls. To calculate the photolysis frequency (jpтD) of 2,3pentanedione (PTD) the mean value of the decay before and after illumination $\left(\mathrm{k}_{\mathrm{W}}\right)$ is subtracted from the decay during illumination. As the slope is typically steeper before than after illumination, subtraction of the corresponding values instead of the mean value give the maximum uncertainty for the resulting photolysis frequency.

$\frac{d[P T D]}{d t}=-k[P T D] \Rightarrow \ln \frac{[P T D]_{t}}{[P T D]_{0}}=t k$

$k_{W}=\frac{k_{W_{\text {before }}+k_{W} \text { after }}}{2} \rightarrow j_{P T D}=k-k_{W}$

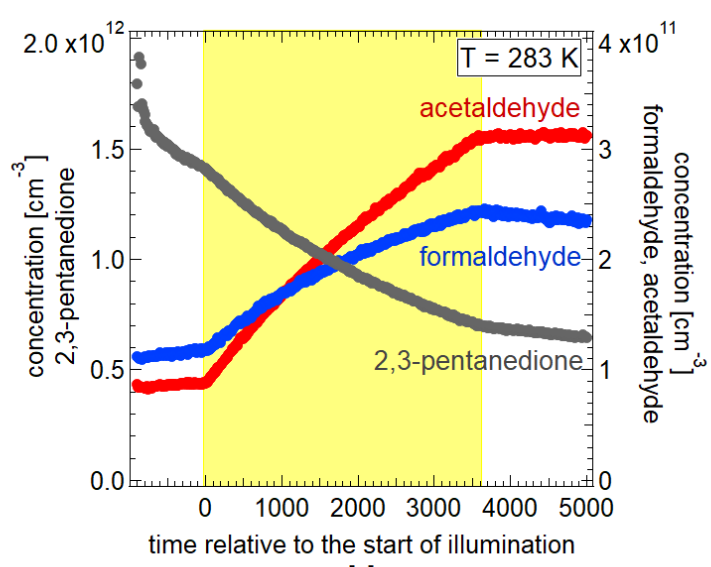

[s]

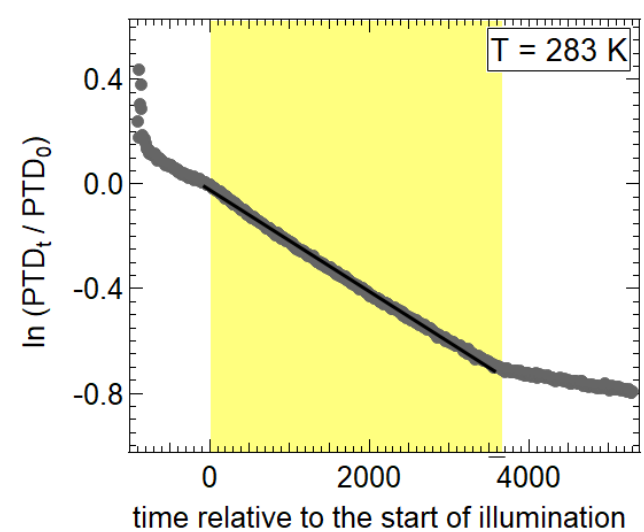

[s]

Figure 5: Concentrations of 2,3-pentanedione, acetaldehyde and formaldehyde during the experiment. Logarithmic depiction of the 2,3-pentandione (PTD) concentration to calculate the photolysis frequency.

The resulting photolysis frequencies and product yields are shown in Fig. 6 as a function of temperature. The photolysis frequencies vary only slightly and there is no significant temperature dependence. The wall loss for the experiment at $213 \mathrm{~K}$ before illumination resulted in a stronger concentration decrease compared to during the illumination. As a result only an upper limit of photolysis frequency, calculated with the wall loss rate after the illumination is given in Fig. 6. It is safe to assume that photolysis was taking place, even though it is difficult to define a frequency, because the formation of products could be observed. The mean value for the four photolysis frequencies from 243 to $298 \mathrm{~K}$ is $\left(1.03 \pm 0.15(1 \sigma) \times 10^{-4}\right) \mathrm{s}^{-1}$. Regarding 
photolysis of 2,3-pentanedione alone, this corresponds to an atmospheric lifetime of about 40 minutes on a summer day. The value for $298 \mathrm{~K}$ is not significantly different from the mean with $\left(1.24 \pm 0.12 \times 10^{-4}\right) \mathrm{s}^{-1}$. Szabo et al. (2011) observed a photolysis frequency of 2,3-pentanedione of $(1.40 \pm 0.06) \times 10^{-5} \mathrm{~s}^{-1}$ at $300 \mathrm{~K}$. This is only $11 \%$ of our measured value. There are two distinct differences in the experimental setup which could explain the discrepancy. First is the fact that Szabo et al. (2011) were adding 1-pentene to trap OH radicals, which may be formed through photolysis of 2,3-pentanedione directly or by the photolysis of one of the reaction products. They account for a $30 \%$ higher photolysis frequency without 1-pentene. Second is the spectral difference of the light sources used. For the experiments of Szabo et al., a combination of two fluorescent tubes with emission maxima at 312 and $365 \mathrm{~nm}$ were used as light source. This results in a narrower spectrum overall. Additionally the absorption spectrum of 2,3-pentanedion shows a minimum at $325 \mathrm{~nm}$, thus the main photolysis was probably only driven by the emission of the fluorescent tube with a peak wavelength at $365 \mathrm{~nm}$. Bouzidi et al. (2014) measured at 298 $\mathrm{K}$ a photolysis frequency of $(3.6 \pm 0.03) \times 10^{-5} \mathrm{~s}^{-1}$ and $(4.3 \pm 0.03) \times 10^{-5} \mathrm{~s}^{-1}$ with and without an $\mathrm{OH}$ radical scavenger. These are already higher values than the results of Szabo et al. But the value in absence of an $\mathrm{OH}$ radical scavenger is only $35 \%$ and hence significantly lower than the value we have observed. A major difference is that Bouzidi et al. (2014) uses 2,3pentanedione at concentrations of 12-48 ppm, while we use concentrations of $20-71 \mathrm{ppb}$. Thus it is possible that recombination process play a larger role than in our experiments. As for the experiments reported by Szabo et al., (2011) one major difference is the light source used (broadband UV lamps: 330-480 nm with a maximum near $370 \mathrm{~nm}$ ).

The yields of the products of acetaldehyde and formaldehyde were determined, using a simple kinetic model applying the software KinSim (Peng and Jimenez, 2019) in Igor Pro. The model accounted for the wall loss of 2,3-pentanedione as well as the photolysis and consecutive formation of formaldehyde and acetaldehyde with the yields $\mathrm{x}$ and $\mathrm{y}$. The rate for the wall loss was set as the mean value $\mathrm{k}_{\mathrm{w}}$. The yields and the photolysis rates were fitted to the measured concentration profiles. The resulting product yields are shown in Fig. 6b, ignoring the experiment at $213 \mathrm{~K}$ due to the strong wall losses. The error bars reflect mainly the uncertainties implied by the wall losses, and to a smaller extent those of the quantification by the PTR-MS measurement. The yields for acetaldehyde are always higher than for formaldehyde and a strong positive temperature dependence can be observed. As a temperature dependence of the photolysis itself can be ruled out the different yields have to be accounted for a change in the reaction mechanism. As there are a lot of possible pathways after the primary photolysis, either the reaction pathways to the formation of acetaldehyde and formaldehyde are thermodynamically controlled and decrease with temperature or other pathways are gaining in significance with lower temperatures. One of the formation reactions of formaldehyde in the reaction mechanism given by Bouzidi et al. (2014 and 2015) is the reaction of $\mathrm{CH}_{3} \mathrm{O}$ with $\mathrm{O}_{2}$.

345 Its reaction rate has been studied by several groups. These findings are summarised in Wantuck et al. (1987). According to their results the reaction rate at $293 \mathrm{~K}$ is 1.8 times the reaction rate at $243 \mathrm{~K}$, which may explain our observed temperature dependence partially. For the formation of acetaldehyde the reaction of $\mathrm{C}_{2} \mathrm{H}_{5} \mathrm{O}$ with $\mathrm{O}_{2}$ is an important pathway and its reaction rate has been studied by Hartmann et al. (1990) for temperatures between 295 and $411 \mathrm{~K}$. Their expression for the reaction rate implies a 1.5 higher reaction rate for $293 \mathrm{~K}$ than for $243 \mathrm{~K}$. Even though the expression might not be perfect for lower temperatures, it shows that the temperature dependence for this reaction pathway may also be considered as explanation for 
our observations. For a temperature of $298 \mathrm{~K}$ and without $\mathrm{OH}$ radical scavenger Bouzidi et al. (2014) reports yields $0.41 \pm 0.7$, $0.39 \pm 0.6$ and $7.6 \pm 0.005$ for formaldehyde, acetaldehyde, and CO, respectively. The yield for formaldehyde agrees with our observation but the yield for acetaldehyde is significantly lower than the value observed in the AIDA experiments. This may be due to the different analytical techniques used (PTR-MS vs. derivatization followed by HPLC-UV analysis), the different light sources or different wall loss rates in the different simulation chambers.
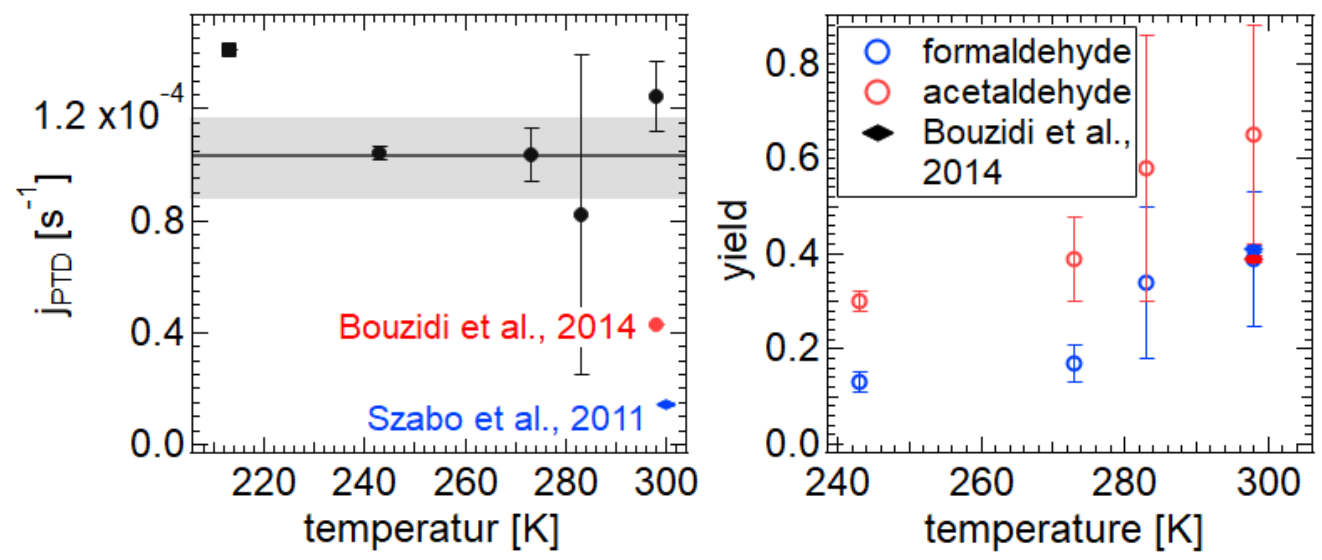

Figure 6: Left: Photolysis frequencies of the photolysis of 2,3-pentanedione for the experiments at different temperatures and the photolysis frequencies measured by Szabo et al. (2011) and Bouzidi et al. (2014). Right: The product yields for the corresponding experiments. The wall loss at $213 \mathrm{~K}$ was too high to perform a model run for the product yield. The photolysis frequency for this temperature shown in the figure is the upper limit with the assumption of a minimal wall loss, equivalent to the value after illumination.

\subsection{Variation of the irradiation spectrum}

In addition to the temperature dependent experiments 2,3-pentanedione was illuminated in intervals of 15 min at $298 \mathrm{~K}$ by changing the spectrum of the emitted light. The different spectra are given in Fig. S4. This was achieved by using only a part

of the LEDs. The aim was to evaluate the wavelength dependence of the photolysis. Furthermore, the results were used to determine a quantum yield of the photolysis. Figure 7 shows the evolution of the 2,3-pentanedione concentration during this experiment. The yellow parts represent the illumination periods with the corresponding peak wavelengths of the LEDs used for each illumination. It should be noted that the resulting spectrum is always broader than the specified peak wavelength (see Fig. S4). For a spectrum which is comprised of the LEDs with the peak wavelengths from $365 \mathrm{~nm}$ to $528 \mathrm{~nm}$ the resulting spectrum has an intensity of about 50\% from $360 \mathrm{~nm}$ to $533 \mathrm{~nm}$ as the FWHM for most LEDs is between 10 and $15 \mathrm{~nm}$. The concentration profile shows that there is no significant photolysis detectable with solely the UV-LEDs in use. This is to be expected regarding the minimum of the absorption spectrum of 2,3-pentanedione between 300 and $350 \mathrm{~nm}$. On the other hand the largest impact has the addition of the LEDs with peak wavelengths of 455, 415 and $405 \mathrm{~nm}$. This is also the region were the absorption spectrum shows a maximum (see Fig. 8). The values for the photolysis frequencies are summarized in Table 1. It is noteworthy that we can still measure a significant photolysis of 2,3-pentanedione even with an illumination produced of 
LEDs with peak wavelengths well beyond the photolysis threshold of $400 \mathrm{~nm}$. In particular, this applies to the illumination periods marked as $455-528 \mathrm{~nm}$ and $475-528 \mathrm{~nm}$.

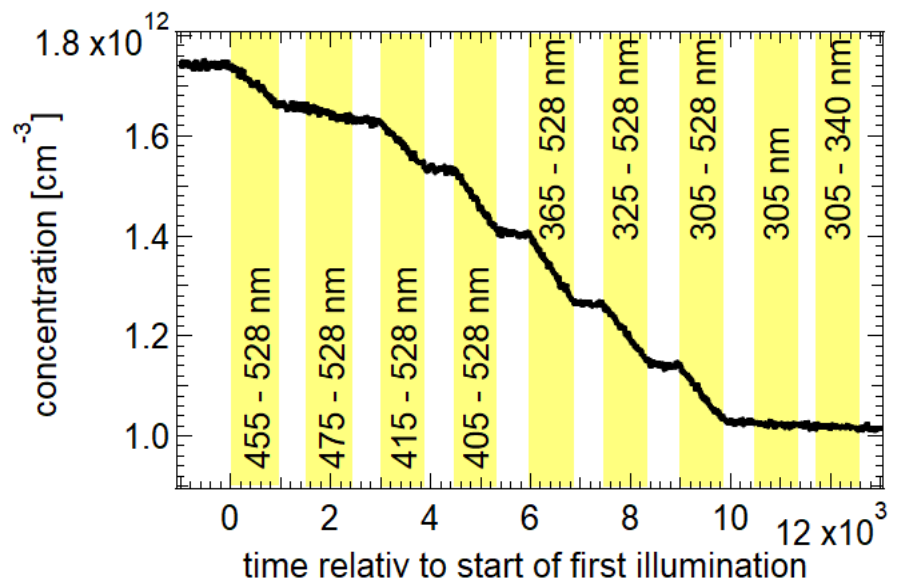

[s]

Figure 7: Concentration of 2,3-pentanedione over the course of several illumination periods with different wavelength ranges of light spectra irradiated at $298 \mathrm{~K}$.

The determination of the quantum yield requires a comparison of the calculated photolysis frequency with the quantum yield equal to one with the observed values (see Table 1). As the photolysis frequency can be calculated as the sum over the discrete values of the radiant flux $J(\lambda)$, the absorption cross section $\sigma(\lambda)$ and the quantum yield $\phi(\lambda)$ the actual quantum yield can be calculated.

$j_{P T D}=\sum_{\lambda_{\text {start }}}^{\lambda_{\text {end }}} \sigma(\lambda) \varphi(\lambda) J(\lambda)$

$\Rightarrow \Phi=\frac{j_{P T D_{\text {observed }}}}{j_{P T D_{\text {calculated }}}}$

It should be kept in mind that this value is only valid for our experimental conditions, this includes the illumination conditions but also chamber specific influences like wall loss effects. One way of accounting for this is to normalise the value with $\mathrm{j}_{\mathrm{NO} 2 \text {,calc. }} / \mathrm{j}_{\mathrm{NO} 2}$ as it was done by Bouzidi et al. (2014) which will be discussed in the following.

The quantum yield is not calculated if only the long wavelengths from 475 to $528 \mathrm{~nm}$ are used or if only the short wavelengths from 305 to $340 \mathrm{~nm}$ are used. This is firstly due to the absorption spectrum of 2,3-pentanedione being only available until 450 $\mathrm{nm}$ (Szabó et al., 2011). Even with a reasonable extrapolation up to $500 \mathrm{~nm}$ the comparison between the photolysis frequencies for the spectral range of 450 to $500 \mathrm{~nm}$ is not valid as the LEDs with a peak wavelength of $528 \mathrm{~nm}$ are ignored. Secondly, due to the minimum in the absorption spectrum in the UV-region the simplification to use a spectrum from 300 to $345 \mathrm{~nm}$ when using LEDs with peak wavelengths from 305 to $340 \mathrm{~nm}$ is underestimating the actual available light. This is true for the complete spectral width but more drastic were the actual spectrum overlaps with the absorption maximum. Furthermore, the 
given uncertainty for the absorption coefficient in the region of $330 \mathrm{~nm}$ is up to $40 \%$, adding considerably to the uncertainty at this wavelength range. Thus, only the values calculated for wavelengths between 300 and $500 \mathrm{~nm}$ were used for comparison, resulting in a mean quantum yield of $0.36 \pm 0.04$. There seems to be no obvious tendency of the quantum yield regarding the spectral characteristics in the respective wavelength range. Szabo et al., (2011) estimated a quantum yield of $0.41 \pm 0.05$ for the photolysis through solar irradiation and Bouzidi et al., (2014) a quantum yield of $0.20 \pm 0.02$ for illumination with fluorescent lamps. Considering the uncertainties there is a good agreement between the value determined by Szabo et al., (2011) and our experiments, while the value of Bouzidi et al. is about $56 \%$ of our value. If we apply a correction according to the procedure used by Bouzidi et al. (2014) we result in a quantum yield of $0.45\left(\mathrm{j}_{\mathrm{NO} 2 \text {,calc. }} / \mathrm{j}_{\mathrm{NO} 2}=1.25\right)$. Hence, the difference is then even larger.

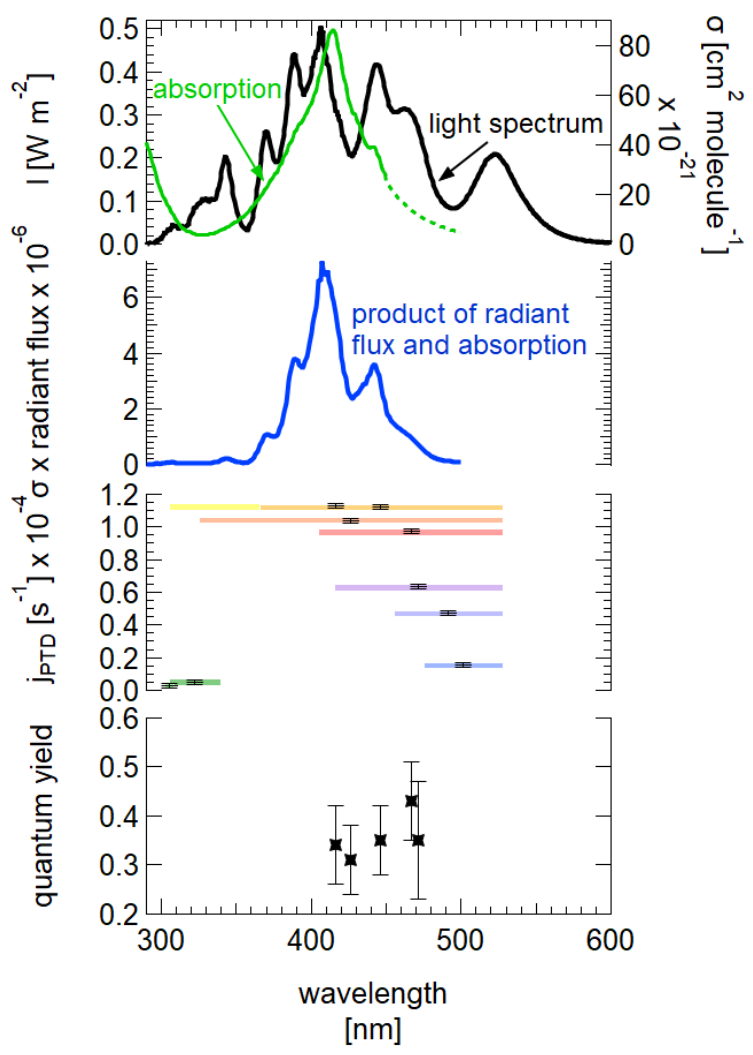

410 Figure 8: Top: Measured spectrum of the light source at $\mathbf{3} \mathbf{~ m}$ height inside the chamber. Absorption spectrum of 2,3pentanedione, extrapolated for the part between 450 and $500 \mathrm{~nm}$ (Data: Szabó et al., 2011). Upper middle: Product of radiant flux and absorption spectrum. Bottom middle: Observed photolysis frequencies for the corresponding illumination at different wavelength ranges. Bottom: Calculated quantum yields for the corresponding wavelength ranges. 


\begin{tabular}{|c|c|c|c|c|}
\hline \multicolumn{2}{|c|}{ calculated values } & \multicolumn{2}{c|}{ observed values } & \\
\hline$\lambda[\mathbf{n m}]$ & jPTD & $\lambda[\mathbf{n m}]$ & jPTD & $\boldsymbol{\phi}$ \\
\hline $470-500$ & $(9.00 \pm 0.90) \times 10^{-6}$ & $475-528$ & $(1.54 \pm 0.13) \times 10^{-5}$ & $*$ \\
$450-500$ & $(3.50 \pm 0.37) \times 10^{-5}$ & $455-528$ & $(4.70 \pm 0.13) \times 10^{-5}$ & $*$ \\
$410-500$ & $(1.82 \pm 0.27) \times 10^{-4}$ & $415-528$ & $(6.33 \pm 0.11) \times 10^{-5}$ & $0.35 \pm 0.12$ \\
$400-500$ & $(2.24 \pm 0.35) \times 10^{-4}$ & $405-528$ & $(9.71 \pm 0.13) \times 10^{-5}$ & $0.43 \pm 0.08$ \\
$360-500$ & $(3.24 \pm 0.52) \times 10^{-4}$ & $365-528$ & $(1.12 \pm 0.01) \times 10^{-4}$ & $0.35 \pm 0.07$ \\
$320-500$ & $(3.32 \pm 0.54) \times 10^{-4}$ & $325-528$ & $(1.04 \pm 0.01) \times 10^{-4}$ & $0.31 \pm 0.07$ \\
$300-500$ & $(3.29 \pm 0.50) \times 10^{-4}$ & $305-528$ & $(1.13 \pm 0.01) \times 10^{-4}$ & $0.34 \pm 0.08$ \\
$300-310$ & $(7.84 \pm 1.64) \times 10^{-7}$ & 305 & $(2.61 \pm 1.36) \times 10^{-6}$ & $*$ \\
$300-345$ & $(3.85 \pm 1.36) \times 10^{-6}$ & $305-340$ & $(5.04 \pm 1.41) \times 10^{-6}$ & $*$ \\
\hline
\end{tabular}

Table 1: Measured and calculated photolysis frequencies of the photolysis of 2,3-pentanedione for different wavelength ranges as well as calculated quantum yields for a temperature of $298 \mathrm{~K}$. The given wavelengths for the observed values refer to the peak wavelengths of the outmost activated LEDs. Values marked as * are not reliable because the difference between the estimated wavelength range and the actual spectral width is affecting the final results too strongly.

\section{Photolysis of dissolved organic components}

To explore the possibilities the light source at the AIDA chamber offers two further experimental series were conducted. One system studied is DTDP, a pyridine-derivative, as a proxy for atmospheric brown carbon components, diluted in aqueous ammonium nitrate and ammonium sulphate solution droplets. A second system consists of ammonium nitrate solution particles, containing iron oxalate as a photosensitizer and pinonic and pinic acid as typical secondary organic components. For both systems only the main preliminary results are presented.

\subsection{Photolysis of 3,5-diacetyl-2,4,6-trimethyl-1,4-dihydropyridine (DTDP)}

DTDP, a pyridine-derivative, is known as an atmospheric brown carbon component (Kampf et al., 2016) which can be formed 430 e.g. by reaction of acetaldehyde and 2,4-pentanedione in the presence of ammonium sulphate. Its absorption spectrum shows a strong band around $380 \mathrm{~nm}$ (cf. Fig. S6). Therefore, we studied its photolysis in aqueous droplets containing ammonium nitrate and ammonium sulphate (weight ratios of DTDP: $\mathrm{NH}_{4} \mathrm{NO}_{3}:\left(\mathrm{NH}_{4}\right)_{2} \mathrm{SO}_{4}$ of 1:2:1) at the temperatures 264, 273, 283, and $293 \mathrm{~K}$ at relative humidities of 70-79 \%. The dry diameter of the aerosol particles was $350 \mathrm{~nm}$. 
The illumination of these droplets leads to the depletion of DTDP in the particle phase corresponding to an average photolysis

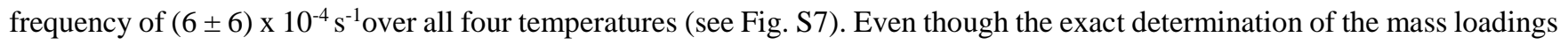
of DTDP in the particle phase turned out to be problematic, we can say that the estimated lifetime of DTDP regarding photolysis in the atmosphere should be in the range of 7-15 minutes. During illumination the production of several components in gas and particle phase could be observed. 16 of these components could be observed in the particle phase at all four temperatures studied as well as in the gas phase for three of the experiments. The gas phase data for the fourth experiment is not available due to technical problems. The mass increases for these 16 components at $293 \mathrm{~K}$ is given in the supplement. Two of these could be identified as 3,5-diacetyl-2,4,6-trimethylpyridine (m/z 205.25) and 3,5-diacetyl-2,6-dimethyl-4hydropyridine (m/z 191.23) by comparison with results of Mitsunobu et al. (1971) and Memarian et al. (2004). Two stable aromatic compounds formed through elimination of $\mathrm{H}_{2}, \mathrm{CH}_{3}$, respectively. The formation of these products is temperature dependent as shown in Fig. 9 for the case of 3,5-diacetyl-2,4,6-trimethylpyridine. Further molecular structures e.g. by elimination of $\mathrm{CO}$ are possible and a corresponding mass to charge ratio can be found, but a more detailed characterization still needs to be done.<smiles>CC(=O)c1c(C)nc(C)c(C(C)=O)c1C</smiles>

205.25

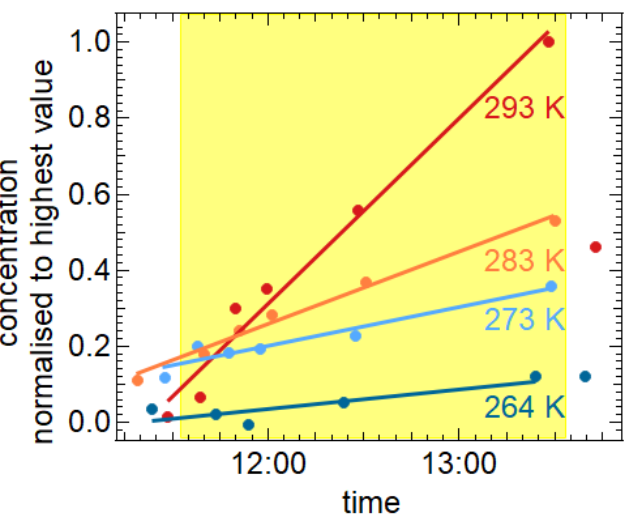<smiles>CC(=O)C1=C(C)NC(C)=C(C(C)=O)C1C</smiles>

207.27

\section{7}

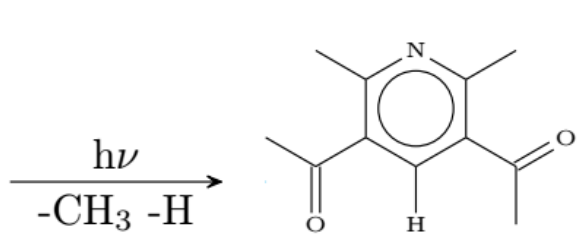

191.23

Figure 9: Mass increase over the illumination period of the mass peak at $\mathbf{m} / \mathbf{z}=\mathbf{2 0 5}$ in the particle phase, identified as 3,5-diacetyl- 


\subsection{Depletion of pinic and pinonic acid by iron oxalate as photosensitizer}

The illumination of iron oxalate charge-transfer-complexes leads to the production of radicals particularly OH radicals.

Oxalic acid itself does not decompose through solar illumination. But through the complexation with $\mathrm{Fe}^{3+}$-ions, absorption in

the UV and visible region is possible (Zuo and Hoigné, 1994; Cooper and DeGraff, 1971, Pozdnyakov et al., 2008). Detailed descriptions of the photolytic decomposition of the oxalic acid and the formation of radicals can be found in Chen et al. (2007 and 2008) and Pozdnyakov et al. (2008). The radicals can consequently react with water and the organic compounds in the aerosol particles. We studied the depletion of two organic acids in aqueous droplets containing also ammonium nitrate and iron oxalate at temperatures of 283,243 , and $213 \mathrm{~K}$ at relative humidities of 88,72 , and $55 \%$, respectively. Pinonic and pinic acids are well known oxidation products of $\alpha$-pinen (Christoffersen et al., 1998; Yu et al. 1998) which is, alongside other terpenes, emitted into the atmosphere in large quantities (Guenther et al., 2012). The aerosol particles were generated by dispersing an aqueous solution of $0.0065 \mathrm{~mol} \mathrm{l}^{-1}$ pinonic acid, $0.0073 \mathrm{~mol}^{-1}$ pinic acid, $0.013 \mathrm{~mol}^{-1} \mathrm{NH} 4 \mathrm{NO} 3$, and $0.0021 \mathrm{~mol} \mathrm{l}^{-1}$ iron oxalate or $0,0081 \mathrm{~mol} \mathrm{l}^{-1}$ oxalate in the reference experiment. The resulting dry particle diameters were $350 \mathrm{~nm}$. Mass spectrometric data show a decrease in the concentrations of the two acids in the particle phase during illumination, with the strongest decrease at the warmest temperature (283 K) (see Fig. 10) and a negligible concentration change for pinic acid at $213 \mathrm{~K}$. Several masses increase during illuminations, of which three could be identified as $\mathrm{C}_{8} \mathrm{H}_{12} \mathrm{O}_{5}$, $\mathrm{C}_{10} \mathrm{H}_{15} \mathrm{NO}_{6}$ and $\mathrm{C}_{10} \mathrm{H}_{15} \mathrm{NO}_{7}$ (see Fig. 10, last panel). Decomposition of pinic and pinonic acid as well as the formation of products reduce significantly with temperature, which might be partially due to the increased viscosity of the aerosol particles. The evolution of particle diameter, relative humidity and temperature for the experiment at $283 \mathrm{~K}$ can be found in Fig. S8. A reference experiment at $283 \mathrm{~K}$ with oxalic acid, pinonic acid, and $\mathrm{NH}_{4} \mathrm{NO}_{3}$ shows no distinct reduction in the pinonic acid concentration during illumination. Our analysis results first order rate coefficients of $2-5 \times 10^{-4} \mathrm{~s}^{-1}$ for the decay of pinonic acid at 283,243 and $213 \mathrm{~K}$ as well as $3-5 \times 10^{-4} \mathrm{~s}^{-1}$ for pinic acid at 283 and $243 \mathrm{~K}$.

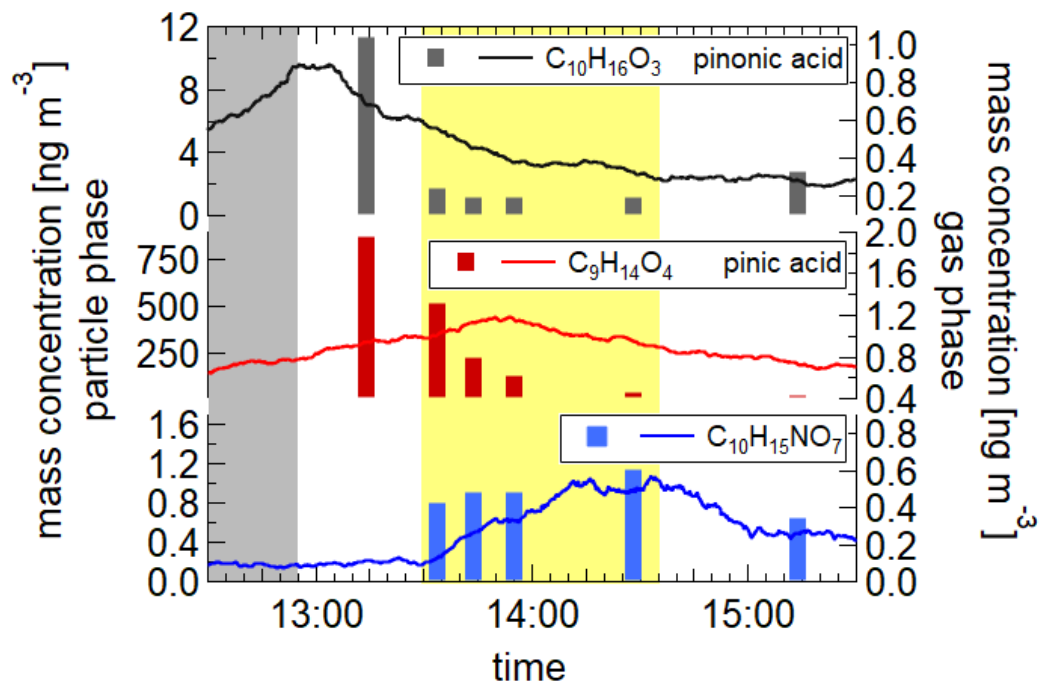


Figure 10: Mass concentration of pinic and pinonic acid, as well as one of the identified products. Bars: Particle phase; line: Gas phase; grey shading: Introduction of aerosol into the AIDA chamber; yellow: Illumination period. Pinic and pinonic acid reduce during illumination while the product $\mathrm{C}_{10} \mathrm{H}_{15} \mathrm{NO}_{7}$ increases. Due to its instable peroxy structure the product concentration declines after the end of the illumination.

These results demonstrate that iron oxalate acts as photosensitizer, which can potentially contribute to degradation of organic compounds in aqueous aerosol particles.

\section{Conclusions}

With the construction of a light source for the AIDA chamber, aerosol formation and ageing studies as well as cloud processes can now be extended including illumination with light of atmospherically relevant intensities and spectral characteristics. Light intensities comparable to $25 \%$ of a clear summer day or $44 \%$ of a clear winter day in Karlsruhe are possible. This was achieved by using a combination of LEDs with 11 different peak wavelengths from $305 \mathrm{~nm}$ to $528 \mathrm{~nm}$, with the additional possibility to change the irradiation spectrum and photon flux at any point during the experiments. Since the LEDs emit only very little IR radiation the deterioration of the excellent temperature homogeneity of the simulation chamber is relatively small with 0.7 $\mathrm{K} / \mathrm{h}$. Therefore, the investigation of the interaction of light with gas phase components, aerosols as well as water and ice clouds is now possible for simulated tropic to stratospheric conditions.

Characterization experiments show a photolysis frequency for $\mathrm{NO}_{2}$ of $(1.59 \pm 0.20(1 \sigma)) \times 10^{-3} \mathrm{~s}^{-1}$ in the temperature range between 213-295 K and a spectral shape similar to the solar spectrum in the UV-VIS range.

First experiments with 2,3-pentanedione prove the applicability of the light source at different temperatures and with different irradiation spectra. The formation of the photolysis products acetaldehyde and formaldehyde show a distinct temperature dependence with yields decreasing with decreasing temperature. The photolysis itself is independent of the temperature.

495 From the variation of the irradiation spectrum we conclude that the photolysis of 2,3-pentanedione is possible for wavelengths below $460 \mathrm{~nm}$ with a mean photolysis frequency of $(1.03 \pm 0.15) \times 10^{-4} \mathrm{~s}^{-1}$. The quantum yield for the photolysis was determined as $0.36 \pm 0.04$.

Further experiments with a photosensitizer and brown carbon components show the variability in photo-aging experiments now possible in the AIDA chamber as well as first results. This includes an estimate for the atmospheric lifetime of 3,5diacetyl-2,4,6-trimethyl-1,4-dihydropyridine of $11 \pm 4 \mathrm{~min}$ and the identification of the photolysis products 3,5-diacetyl-2,4,6trimethylpyridine an 3,5-diacetyl-2,6-dimethylpyridine. Additionally a temperature dependent degradation of organic acids in aqueous droplets through the photosensitizer iron-oxalate could be observed.

Although, the light source so far only generates about $1 / 3$ of the maximum solar irradiation at ground level with a substantial intensity gradient throughout the simulation chamber it could be shown that this type of light source allows reproducible 

spectrum. A specific asset of the setup is the large temperature range, over which the studies can be conducted.

\section{Supplement}

The supplement related to this article is available online at:...

\section{Author contributions}

M.V. and J.N. build the light source based on ideas by H.S. and T.L. M.V. and H.S. conducted the experiments with substantial contributions by L.G. (AMS \& CIMS), F.J. (filter samples, absorption measurements), and J.S. (AMS \& PTR-MS). The data were analysed by H.S. and M.V. (light spectra, CIMS, aerosol data), J.S. (AMS \& PTR-MS), B.K. (kinetics). M.V. wrote the 515 manuscript with contributions from all co-authors.

\section{Competing interests}

The authors declare that they have no conflict of interest.

\section{Acknowledgements}

The authors also want to thank the staff of the KIT-IMK-AAF especially Georg Scheurig, Tomasz Chudy, and Steffen Vogt for their technical support. A special thanks is going to GRACE, the graduate school of KIT for financing conferences and the aerosol summer school.

\section{Financial support}

This project/work has received funding from the European Union's Horizon 2020 research and innovation programme through the EUROCHAMP-2020 Infrastructure Activity under grant agreement No 730997.

\section{Data availability}

530 The AIDA light spectrum is available via the KITopen data repository (link/doi).

\section{References}

Aregahegn, K. Z., Nozière, B., George, C.; Organic aerosol formation photo-enhanced by the formation of secondary photosensitizers in aerosols, Faraday Discuss., 165, 123-134, doi: 10.1039/c3fd00044c, 2013.

Atkinson, R., Baulch, D. L., Cox, R. A., Crowley, J. N., Hampson, R. F., Hynes, R. G., Jenkin, M. E., Rossi, M. J., Troe, J.; 535 IUPAC Task Group on Atmospheric Chemical Kinetic Data Evaluation, Atmos. Chem. Phys., 4, 1461, 2004. 
https://doi.org/10.5194/amt-2021-362

Preprint. Discussion started: 20 November 2021

(c) Author(s) 2021. CC BY 4.0 License.
Atmospheric

Measurement

Techniques

Discussions

Atkinson, R., Baulch, D. L., Cox, R. A., Crowley, J. N., Hampson, R. F., Hynes, R. G., Jenkin, M. E., Rossi, M. J., Troe, J.; Evaluated kinetic and photochemical data for atmospheric chemistry: Volume II - Gas phase reactions of organic species, Atmos. Chem. Phys., 6, 3625-4055, doi: 10.5194/acp-6-3625-2006, 2006.

Bartl, J., Baranek, M.; Emissivity of aluminium and its importance for radiometric measurement, Meas. Sci. Rev., 4, 31-36, 2004.

Baltrusaitis, J., Schuttlefield, J., Jensen, J. H., Grassian, V. H.; FTIR spectroscopy combined with quantum chemical calculations to investigate adsorbed nitrate on aluminium oxide surfaces in the presence and absence of co-adsorbed water, Phys. Chem. Chem. Phys., 9, 4970-4980, doi: 10.1039/b705189a, 2007.

Bohn, B., Zilken, H.; Model-aided radiometric determination of photolysis frequencies in a sunlit atmosphere simulation chamber, Atmos. Chem. Phys., 5, 191-206, doi: 10.5194/acp-5-191-2005, 2005.

Bouzidi, H., Fittschen, C., Coddeville, P., Tomas, A.; Photolysis of 2,3-pentanedione and 2,3-hexanedione: Kinetics, quantum yields, and product study in a simulation chamber, Atmos. Environ., 82, 250-257, doi: 10.1016/j.atmosenv.2013.10.039, 2014. Bouzidi, H., Djehiche, M., Gierczak, T., Morajkar, P., Fittschen, C., Coddeville, P., Tomas, A., Low-Pressure Photolysis of 2,3-Pentanedione in Air: Quantum Yields and Reaction Mechanism, 119, 12781-12789, doi: 10.1021/acs.jpca.5b09448, 2015.

550 Burdock G. A.; Fenaroli's handbook of flavor ingredients, CRC press, $4^{\text {th }}$ edition, S.1411-1412, 2002.

Campo, E., Ferreira, V., Escudero, A., Marqués, J. C., Cacho, J.; Quantitative gas chromatography-olfactometry and chemical quantitative study of the aroma of four Madeira wines, Analytica Chimica Acta, 563, 180-187, doi: 10.1016/j.aca.2005.10.035, 2006.

Chen, J., Zhang, H., Tomov, I. V., Wolfsberg, M., Ding, X., Rentzepis, P. M.; Transient structures and kinetics of the 555 ferrioxalate redox reaction studied by time-resolved EXAFS, optical spectroscopy, and DFT, J. Phys. Chem. A, 111, 93269335, doi: 10.1021/jp0733466, 2007.

Chen, J., Zhang, H., Tomov, I. V., Rentzepis, P. M., Electron transfer mechanism and photochemistry of ferrioxalate induced by excitation in the charge transfer band, Inorg. Chem., 47, 2024-2032, doi: 10.1021/ic7016566, 2008.

Christoffersen, T. S., Hjorth, J., Horie, O., Jensen, N. R., Kotzias, D., Molander, L. L., Neeb, P., Ruppert, L., Winterhalter, R.,

560 Virkkula, A., Wirtz, K., Larsen, B. R.; Cis-pinic acid, a possible precursor for organic aerosol formation from ozonolysis of a-pinene, Atmos. Environ., 32, 1657-1661, doi: 10.1016/S1352-2310(97)00448-2, 1998.

Ciuraru, R., Fine, L., Pinxteren, M. V., D'Anna, B, Herrmann, H, George, C.; Unravelling New Processes at Interfaces: Photochemical Isoprene Production at the Sea Surface, Environ. Sci. Technol, 49, 13199-13205, doi: 10.1021/acs.est.5b02388, 2015.

565 Cooper, G. D., DeGraff, B. A.; Photochemistry of the ferrioxalate system, J. Phys. Chem., 75, 2897-2902, 1971.

Fu, H., Ciuraru, R., Dupart, Y., Passananti, M., Tinel, L., Rossignol, S., Perrier, S., Donaldson, J. D., Chen, J., George, C.; Photosensitized Production of Atmospherically Reactive Organic Compounds at the Air/Aqueous Interface, JACS, 137, 83488351, doi: 10.1021/jacs.5b04051, 2015. 
https://doi.org/10.5194/amt-2021-362

Preprint. Discussion started: 20 November 2021

(c) Author(s) 2021. CC BY 4.0 License.
Atmospheric

Measurement

Techniques

Discussions

George, C., Ammann, M., D'Anna, B., Donaldson, D. J., Nizkorodov, S. A.; Heterogeneous Photochemistry in the Atmosphere,

Chem. Rev., 115, 4218-4258, doi: 10.1021/cr500648z, 2015.

Goldstein, A. H., Galbally, I. E.; Known and unexplored organic constituents in the earth's atmosphere, Eviron. Sci. Techn., 41, 1514-1421, doi: 10.1021/es072476p, 2007.

Grosjean, E., Grosjean, D.; The gas-phase reaction of alkenes with ozone: Formation yields of carbonyls from biradicals in ozone-alkene-cyclohexane experiments, Atmos. Environ., 32, doi: 10.1016/S1352-2310(98)80005-8, 1998.

Guenther, A. B., Jiang, X., Heald, C. L., Sakulyanontvittaya, T., Duhl, T., Emmons, L. K., Wang, X.; The model of emissions of gases and aerosols from nature version 2.1 (MEGAN2.1): An extended and updated framework for modeling biogenic emissions, Geosci. Model Dev., 5, 1471-1492, doi: 10.5194/gmd-5-1471-2012, 2012.

Hartmann, D., Karthäuser, J., Sawerysyn, J. P., Zellner, R.; Kinetics and HO2 Product Yield of the Reaction C2H5O + O2 between 295 and 411 K, Ber. Bunsenges. Phys. Chem., 94, 639-645, doi: 10.1002/bbpc.19900940604, 1990.

Harvey, R. B., Stedmann, D. H., Chameides, W.; Determination of the Absolute Rate of Solar Photolysis of $\mathrm{NO}_{2}$, J. Air. Pollut. Acontrol Assoc., 27, 663-666, doi:10.1080/00022470.1977.10470469, 1977.

Herrmann, H., Schaefer, T., Tilgner, A., Styler, S. A., Weller, C., Teich, M., Otto, T.; Tropospheric Aqueous-Phase Chemistry: Kinetics, Mechanisms, and Its Coupling to a Changing Gas Phase, Chem. Rev., 115, 4259-4334, doi: 10.1021/cr500447k, 2015.

Holmes, J. R., O’Brien, R. J., Crabtree, J. H., Hecht, T. A., Seinfeld, J. H.; Measurement of Ultraviolet Radiation Intensity in Photochemical Smog Studies, Environ. Sci. Technol., 7, 519-523, doi: 10.1021/es60078a002, 1973.

Fankhauser A. M., Bourque, M., Almazan, J., Marin, D., Fernandez, L., Hutheesing, R., Ferdousi, N., Tsui, W. G., McNeill, V. F.; Impact of Environmental Conditions on Secondary Organic Aerosol Production from Photosensitized Humic Acid, Environ. Sci. Technol., 54, 5385-5390, doi:10.1021/acs.est.9b07485, 2020.

590 Kampf, C. J., Filippi, A., Zuth, C., Hoffmann, T., Opatz, T.; Secondary brown carbon formation via the dicarbonyl imine pathway : nitrogen heterocycle formation and synergistic effects, Phys. Chem. Chem. Phys., 18, 18353-18364, doi: 10.1039/C6CP03029G, 2016.

Kercher, J. P., Fogleman, E. A., Koizumi, H., Sztáray, B., Baer, T.; Heats of formation of the propionyl ion and radical and 2,3-pentanedione by threshold photoelectron photoion coincidence spectroscopy, J. Phys. Chem. A, 109, 939-946, doi: 595 10.1021/jp0458497, 2005.

Lehtipalo, K., Yan, C., Dada, L., Bianchi, F., Xiao, M., Wagner, R., Stolzenburg, D., Ahonen, L. R., Amorim, A., Baccarini, A., Bauer P. S., Baumgartner, B., Bergen, A., Bernhammer, A.-K., Breitenlechner, M., Brilke, S., Buchholz, A., Stephany Buenrostro Mazon, S., Chen, D., Chen, X., Dias, A., Dommen, J., Draper, D. C., Duplissy, J., Ehn, M., Finkenzeller, H., Fischer, L., Frege, C., Fuchs, C., Garmash, O., Gordon, H., Hakala, J., He, X., Heikkinen, L., Zeinritzi, M., Helm, J. C., 600 Hofbauer, V., Hoyle, C. R., Jokinen, T., Kangasluoma, J., Kerminen, V.-M., Kim, C., Kirkby, J., Kontkanen, J., Kürten, A., Lawler, M. J., Mai, H., Mathot, S., Mauldin R. L., Molteni, U., Nichman, L., Nie, W., Nieminen, T., Ojdanic, A., Onnela, A., Passananti, M., Petäjä, T., Piel, F., Pospisilova, V., Quéléver, L. L. J., Rissanen, M P., Rose, C., Sarnela, N., Schallhart, S., 
https://doi.org/10.5194/amt-2021-362

Preprint. Discussion started: 20 November 2021

(c) Author(s) 2021. CC BY 4.0 License.
Atmospheric

Measurement

Techniques

Discussions

Schuchmann, S., Sengupta, K., Simon, M., Sipilä, M., Tauber, C., Tomé, A., Tröstl, J., Väisänen, O., Vogel, A. L., Volkamer, R., Wagner, A. C., Wang, M., Weitz, L., Wimmer, D., Ye, P., Ylisirniö, A., Zha, Q., Carslaw, K. S., Curtius, J., Donahue, N. Multicomponent new particle formation from sulfuric acid, ammonia, and biogenic vapors, Sci. Adv., 4, doi: 10.1126/sciadv.aau5363, 2018.

Memarian, H. R., Bagheri, M., Döpp, D.; Synthesis and photochemistry of novel 3,5-diacetyl-1,4-dihydropyridines. II [1], Monatshefte für Chemie, 135, 833-838, doi: 10.1007/s00706-003-0139-5, 2004.

610 Mitsunobu, O., Matsumoto, S., Wada, M., Masuda, H.; Photooxidation of 1,4-Dihydropyridines, Bulletin of the Chemical Society of Japan, 45, 1453-1457, 1972.

Möhler, O., Stetzer, O., Schäfers, S., Linke, C., Schnaiter, M., Tiede, R., Saathoff, H., Krämer, M., Mangold, A., Budz, P., Zink, P., Schreiner, J., Mauersberger, K., Haag, W., Kärcher, B., Schurath, U.; Experimental investigation of homogeneous freezing of sulphuric acid particles in the aerosol chamber AIDA, Atmos. Chem. Phys., 2, 211-223, doi: 10.5194/acp-3-211$6152003,2003$.

Monge, M. E., Rosenørn, T., Favez, O., Müller, M., Adler, G., Riziq, A. A., Rudich, Y., Herrmann, H., George, C., D'Anna, B.; Alternative pathway for atmospheric particles growth, PNAS, 109, 6840-6844, doi: 10.1073/pnas.1120593109, 2012.

Müller, L., Reinnig, M.-C., Naumann, K. H., Saathoff, H., Mentel, T.F., Donahue, N. M. and Hoffmann, T.: Formation of 3methyl-1,2,3-butanetricarboxylic acid via gas phase oxidation of pinonic acid - a mass spectrometric study of SOA aging, Atmos. Chem. Phys., 12, 1483-1496, doi:10.5194/acp-12-1483-2012, 2012.

Navea, J.G., Grassian, V.H.; Photochemistry of Atmospheric Particles, Encyclopedia of Interfacial Chemistry: Surface Science and Electrochemistry, 1-10, doi: 10.1016/B978-0-12-409547-2.13210-X, 2017.

Paulsen, D., Dommen, J., Kalberer, M., Prévôt, A.S.H., Richter, R., Sax, M., Steinbacher, M., Weingartner, E., Baltensperger, U., Secondary organic aerosol formation by irradiation of 1,3,5- trimethylbenzene- $\mathrm{NO}_{\mathrm{x}}-\mathrm{H}_{2} \mathrm{O}$ in a new reaction chamber for atmospheric chemistry and physics, Environ. Sci. Technol., 39, 2668-2678, doi: 10.1021/es0489137, 2005.

Peng, Z., Jimenez, J. L.; KinSim: A Research-Grade, User-Friendly, Visual Kinetics Simulator for Chemical-Kinetics and Environmental-Chemistry Teaching, J. Chem. Educ., 96, 806-811, doi: 10.1021/acs.jchemed.9b00033, 2019.

Platt, S. M., El Haddad, I., Zardini, A. A., Clairotte, M., Astorga, C., Wolf, R., Slowik, J. G., Temime-Roussel, B., Marchand, N., Ježek, I., Drinovec, L., Močnik, G., Möhler, O., Richter, R., Barmet, P., Bianchi, F., Baltensperger, U., Prévôt, A. S. H.;

630 Secondary organic aerosol formation from gasoline vehicle emissions in a new mobile environmental reaction chamber, Atmos. Chem. Phys., 13, 9141-9158, doi: 10.5194/acp-13-9141-2013, 2013.

Pozdnyakov, I. P., Kel, O. V., Plyusnin, V. F., Grivin, V. P., Bazhin, N. M.; New insight into photochemistry of ferrioxalate, J. Phys. Chem. A, 112, 8316-8322, doi: 10.1021/jp8040583, 2008.

Reeser, D. I., George, C, Donaldson, D. J.; Photooxidation of halides by chlorophyll at the air-salt water interface, J. Phys. Chem. A, 113, 8591-8595, doi: 10.1021/jp903657j, 2009. 
https://doi.org/10.5194/amt-2021-362

Preprint. Discussion started: 20 November 2021

(c) Author(s) 2021. CC BY 4.0 License.
Atmospheric

Measurement

Techniques

Discussions

Ren, Y., Grosselin, B., Daële, V., Mellouki, A., Investigation of the reaction of ozone with isoprene, methacrolein and methyl vinyl ketone using the HELIOS chamber, Faraday Discuss., 200, 289-311, doi: 10.1039/c7fd00014f, 2017.

Rohrer, F., Bohn, B., Brauers, T., Brüning, D., Johnen, F. J., Wahner, A., Kleffmann, J.; Characterisation of the photolytic HONO-source in the atmosphere simulation chamber SAPHIR, Atmos. Chem. Phys, 5, 2189-2201, doi: 10.5194/acp-5-21892005, 2005.

Romano, A., Capozzi, V., Spano, G., Biasioli, F.; Proton transfer reaction-mass spectrometry: online and rapid determination of volatile organic compounds of microbial origin, Appl. Microbiol. Biotechnol., 99, 3787-3795, doi: 10.1007/s00253-0156528-y, 2015.

Rossignol, S., Aregahegn, K. Z., Tinel, L., Fine, L., Nozière, B., George, C.; Glyoxal induced atmospheric photosensitized chemistry leading to organic aerosol growth, Environ. Sci.Technol., 48, 3218-3227, doi: 10.1021/es405581g, 2014.

Rubasinghege, G., Grassian, V. H.; Photochemistry of adsorbed nitrate on aluminum oxide particle surfaces, J. Phys. Chem. A, 27,7818-7825, doi: 10.1021/jp902252s, 2009.

Saathoff, H., Möhler, O., Schurath, U., Kamm, S., Dippel, B. and Mihelcic, D.; The AIDA soot aerosol characterisation campaign 1999, Aerosol Science, 34, 1277 - 1296, doi:10.1016/S0021-8502(03)00363-X, 2003.

650 Saathoff, H. Naumann, K.-H., Möhler, O., Jonsson, Å. M., Hallquist, M., Kiendler-Scharr, A., Mentel, Th. F., Tillmann, R., Schurath, U.; Temperature dependence of yields of secondary organic aerosols from the ozonolysis of $\alpha$-pinene and limonene, Atmos. Chem. Phys., 9, 1551-1577, doi: 10.5194/acp-9-1551-2009, 2009.

Scaiano, J C., Temperature dependence of the photochemistry of o-methylacetophenone. A laser flash photolysis study., Chem. Phys. Lett., 73, 319-322, doi: 10.1016/0009-2614(80)80381-2, 1980.

655 Seinfeld J. H., Pandis, S. P.; Atmospheric Chemistry and Physics From Air Pollution to Climate Change, John Wiley \& Sons, Hoboken, New Jersey, $2^{\text {nd }}$ edition, 116-117, 2006.

Sharpless, C. M., Blough, N. V.; The importance of charge-transfer interactions in determining chromophoric dissolved organic matter (CDOM) optical and photochemical properties, Environ. Sci.: Processes Impacts, 16, 654-671, doi: 10.1039/c3em00573a, 2014.

660 Shetter, R. E., Davidson, J. A., Cantrell, C. A., Burzynski Jr., N. J., Calvert, J. G.; Temperature dependence of the atmospheric photolysis rate coefficient for $\mathrm{NO}_{2}$, JGR Atmospheres, 93, 7113-7118, doi: 10.1029/JD093iD06p07113, 1988.

Smith, G. D., Molina, L. T., Molina, M. J.; Temperature dependence of O(1D) quantum yields from the photolysis of ozone between 295 and 338 nm, J. Phys. Chem. A, 104, 8916-8921, doi: 10.1021/jp001006d, 2000.

Stocker T. F., Qin, D., Plattner, G.-K., Tignor, M., Allen, K. S., J.Boschung, Nauels, A., Xia, Y., Bex, V., Midgley, M. P.; 665 CLIMATE CHANGE 2013, The Physical Science Basis. Contribution of Working Group 1 to the Fifth Assessment Report of the Intergovernmental Panel on Climate Change, Cambridge University Press, Cambridge, 1-2228, 2013.

Szabó, E., Djehiche, M., Riva, M., Fittschen, C., Coddeville, P., Sarzyński, D., Tomas, A., Dóbé, S.; Atmospheric chemistry of 2,3-pentanedione: Photolysis and reaction with OH radicals, J. Phys. Chem. A, 115, 9160-9168, doi:10.1021/jp205595c, 2011. 
https://doi.org/10.5194/amt-2021-362

Preprint. Discussion started: 20 November 2021

(c) Author(s) 2021. CC BY 4.0 License.
Atmospheric

Measurement

Techniques

Discussions

670 Tadić, J., Moortgat, G. K., Wirtz, K.; Photolysis of glyoxal in air, Journal of Photochemistry and Photobiology A: Chemistry, 177, 116-124, doi: 10.1016/j.jphotochem.2005.10.010, 2006.

Wagner, R., Bunz, H., Linke. C., Möhler, O., Naumann, K.-H., Saathoff, H. Schnaiter, M., Schurath, U.; Chamber Simulations of Cloud Chemistry: The AIDA Chamber, In: Barnes, I., Rudzinky, K. J. (eds), Nato Science Series: IV: Earth an Environmental Science, Springer, Dordrecht, 62, doi: 10.1007/1-4020-4232-9_5, 2006.

675 Wang, J., Doussin, J. F., Perrier, S., Perraudin, E., Katrib, Y., Pangui, E., Picquet-Varrault, B.; Design of a new multi-phase experimental simulation chamber for atmospheric photosmog, aerosol and cloud chemistry research, Atmos. Meas. Tech., 4 , 2465-2494, doi: 10.5194/amt-4-2465-2011, 2011.

Wantuck, P. J., Oldenburg, R. C., Baughcum, S. L., Winn, K. R.; Removal Rate Constant Measurements for CH3O by O2 over the 298-973 K Range, J. Phys. Chem., 91, 4653-4655, doi: 10.1021/j100302a004, 1987.

680 Wiesen, P.; Photooxidant Studies Using the European Photoreactor EUPHORE, Transp. Chem. Transform. Troposph., 2, 155162, doi:10.1007/978-3-642-56722-3_25, 2001.

$\mathrm{Yu}$, J., Flagan, R. C., Seinfeld, J. H.; Identification of products containing -COOH, -OH, and -C=O in atmospheric oxidation of hydrocarbons, Environ. Sci. Technol., 32, 2357-2370, doi: 10.1021/es980129x, 1998.

Yuan, B., Koss, A. R., Warneke, C., Coggon, M., Sekimoto, K., de Gouw, J. A.; Proton-Transfer-Reaction Mass Spectrometry:

685 Applications in Atmospheric Sciences, Chem. Rev., 117, 13187-13229, doi: 10.1021/acs.chemrev.7b00325, 2017.

Zádor, J., Turányi, T., Wirtz, K., Pilling, M. J.; Measurement and investigation of chamber radical sources in the European Photoreactor (EUPHORE), J. Atmos. Chem., 55, 147-166, doi: 10.1007/s10874-006-9033-y, 2006.

Zuo, Y., Hoigné, J.; Photochemical decomposition of oxalic, glyoxalic and pyruvic acid catalysed by iron in atmospheric waters, Atmos. Environ., 28, 1231-1239, doi: 10.1016/1352-2310(94)90270-4, 1994.

690

695 